\title{
Oceanic response to atmospheric forcing derived from different climatic data sets. Intercomparison study for the Black Sea
}

\author{
Joamna V. STANEVA, Emil V. STANEV \\ Department of Meteorology and Geophysics, Faculty of Physics, University of Sofia, 5, James Bourchier street, \\ 1126 Sofia, Bulgaria
}

(Received 24/06/96, revised 20/06/97, accepted 27/06/98)

\begin{abstract}
Available climatic and atmospheric analysis data have been used to prepare forcing functions for the Black Sea numerical model, based on the Bryan-Semtner-Cox Modular Ocean Model and including parameterizations for the atmosphere-ocean exchange, inflow through the strait of Bosphorus and the Mediterranean plume. Atmospheric data from different sources are compared and the drawbacks of some of them illustrated. A new wind stress data set, based on ship observations, is prepared. Compared to the existing wind stress estimates, the present ones use additional data and more accurate parameterization of the boundary layer physics. The intercomparison between forcing data sets is focused on the heat flux and freshwater flux at the sea surface.

The model simulates adequately vertical stratification, seasonal variability and horizontal patterns. Five data sets for heat flux, freshwater flux and wind stress are used in different combinations to study the model response. The large differenees between the simulations, forced by different wind stress and identical thermohaline forcing, justify the computation of the new wind stress. Though the forcing data used are perhaps close to the best available at the moment for the Black Sea, the model simulations range in large intervals and some of them are very poor. The model responses to forcing functions of different origin give rough estimates on the possible errors in present-day simulations. Some inconsistencies give clear indications that further verifications, improvements of the forcing functions, and intercomparisons between the responses simulated by the ocean circulation models are needed. (C) Elsevier, Paris
\end{abstract}

\section{Black Sea / water exchange / heat exchange / wind stress / numerical modelling}

Résumé - Réponse de l'océan au forçage atmosphérique en mer Noire. Des données climatiques et atmosphériques de la littérature ont été utilisées pour déterminer les fonctions de forçage dans une modélisation numérique de la mer Noire. Fondé sur le modèle modulaire de l'océan de Bryan-Semtner-Cox, le présent modèle prend en compte les échanges entre l'océan et l'atmosphère, l'apport par le détroit du Bosphore et le panache méditerranéen. Des données atmosphériques de différentes origines sont comparées et leurs défauts éventuels sont indiqués. Une représentation plus précise de la couchelimite est obtenue en considérant un nouveau paramètre, la tension du vent, fournie par des observations de navires. La comparaison des séries de données porte sur les flux de chaleur et d'eau douce à travers la surface libre. Le modèle représente correctement la stratification verticale, la variabilité saisonnière et les répartitions horizontales. Cinq séries de données, pour le flux de chaleur, le flux d'eau douce et la tension de vent, sont utilisées dans différentes combinaisons afin d'étudier la réponse du modèle. Avec plusieurs tensions de vent et un même forçage thermohalin, de grandes différences apparaissent entre les simulations, justifiant le calcul de la nouvelle tension de vent. Bien que les données utilisées pour le forçage soient probablement parmi les meilleures actuellement disponibles pour la mer Noire, les résultats se situent dans de larges intervalles et certains modèles sont plutôt médiocres. Le modèle donne une estimation des erreurs que l'on peut attendre dans le cadre des modèles forcés par des données actuelles. Des incohérences entre différentes simulations montrent la nécessité de vérifications, améliorations des forçages et intercomparaisons de résultats. (C) Elsevier, Paris

mer Noire / échange d'eau / échange de chaleur / tension du vent / modélisation numérique 


\section{INTRODUCTION}

The Black Sea is located hetween $40^{\circ} 56^{\circ}$ and $46^{\circ} 33^{\prime} \mathrm{N}$ and $27^{\circ} 27^{\prime}$ and $41^{\circ} 42^{\prime} \mathrm{E}$, and is part of the European Mediterranean Sea (figure 1). The Straits of Bosphorus and Kerch link the Black Sea with the Marmara and the Azov Seas. The longest east-west section is about $1148 \mathrm{~km}$, the narrowest meridional section (between the Crimea Peninsula and the Turkish coast) is $258 \mathrm{~km}$. The surface of the sea is $4.2 \times 10^{5} \mathrm{~km}^{2}$, its volume $5.3 \times$ $10^{5} \mathrm{~km}^{3}$ and its mean depth about $1300 \mathrm{~m}$. River runoff, dominated by the Danube, Dnepr and Dnestr Rivers, dilutes the surface water in the western Black Sea, as clearly seen in the Sea Surface Salinity (SSS) patterns (figure $2 a$ ). The water exchange through the narrow and shallow Strait of Bosphorus is small, with upper flow salinity about half that of the Mediterranean Sea. The ratio between the volume of the Black Sea and the water exchanged with the Sea of Marmara (300 $\mathrm{km}^{3} \mathrm{y}^{-1}$, [49]) gives an estimate for the time residence of about 2000 years. This large number illustrates that the Black Sea is one of the most isolated ocean areas.
It is accepted in Black Sea oceanography that the large freshwater flux at the sea surface maintains the very stable stratification. This stability reduces the depth of ventilation, and the active layer, responding to the seasonal variability, is limited to $50-150 \mathrm{~m}$. The penetration of surface waters into the deeper layers is due to the sinking Mediterranean water and to the entrained waters from the Cold Intermediate Layer (CIL), [11, 32]. The strong dependence of the circulation on the fresh water balance makes the present day dynamics of the Black Sea and that of the ancient ocean similar, and provides a natural laboratory for testing different concepts of global change with long time scales. The enclosed boundaries and the opportunity to estimate correctly the exchange in the straits permit accurate tuning of the heat and water balance at the sea surface [45].

Interest in the oceanography of shelf and inland seas has resulted in the establishment of several international programmes, e.g. the Co-operative Marine Science programme for the Black Sea (CoMSBlack), the International Atomic Energy Agency programme for radio-

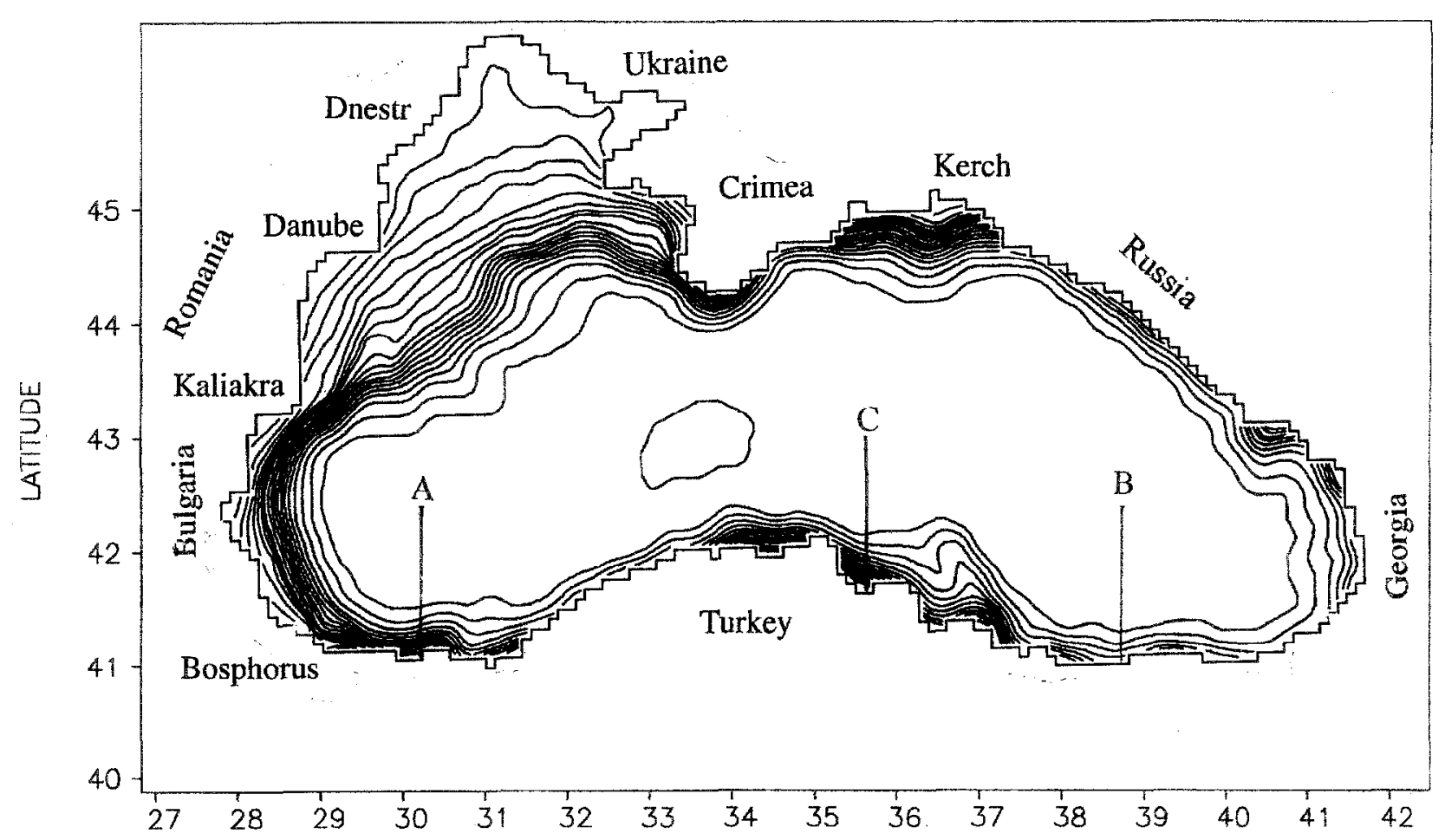

Figure 1. Model topography; The following isolines, illustrating the model levels, are plotted: $2.5,7.5,12.5,17.5,25,35,45,55,65,75,85$, $105,140,185,240,310,400,515,665,870,1145,1470,1820,2125 \mathrm{~m}$. 

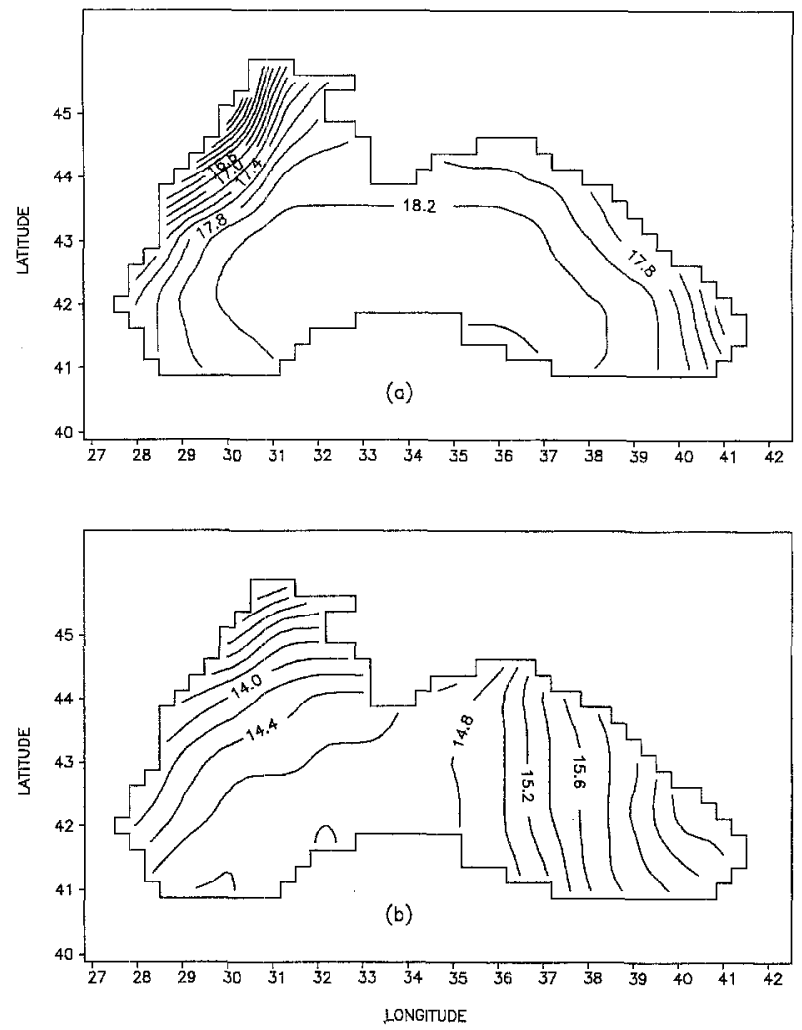

Figure 2. a) Annual mean sea-surface salinity; b) Annual mean seasurface temperature. Climatic data described in text as S-data are used to plot the figures.

active tracers in the Black Sea, the European River Ocean System (EROS) programme and, the NATO-TU Black Sea programme. The modelling component plays an important role in these programmes, but progress in this direction depends in great measure on the availability of boundary conditions. It is recognized that adequate simulations could be achieved if the model forcing is accurately prescribed. This requires intercomparison studies on the existing atmospheric data, which is one of the main issues of the present paper.

Much experience in ocean modelling has been collected from studies on the model response to different forcing. Common databases have been developed, and analyses and improvements of the forcing functions used in ocean modelling are constantly appearing in the literature. So far, however, no co-ordinated efforts have been undertaken by the Black Sea riparian countries to update the existing data for atmospheric forcing in the Black Sea, and there are grounds for speculation as to the realism or comparability of model estimates derived from different models and under different atmospheric forcing. Some of the previous model studies addressed the Black Sea model response from the viewpoint of sensitivity to climatic data and to clifferent combinations of forcing functions $[29,30,43]$. Such a selective approach can provide useful information, assuming that the forcing is correct. In this paper, we address a similar issue in a different way. We always use the same combinations of forcing functions, but investigate the model response to the origin of the forcing. This could provide information about the magnitude of errors that might be expected if inappropriate forcing functions are used.

We compare model forcing functions, based on available data (the only new calculated forcing function is the wind stress). The lack of intercomparison studies on the atmospheric data for the region of the Black Sea is a compelling reason for the analysis of data of different origins, which is also important in order to better understand the responses in the model simulations. Our conclusions are designed to stimulate further improvements of the forcing functions and model intercomparisons.

\section{THE BLACK SEA MODEL}

This study uses the Pakanowski et al. [33] Modular Ocean Model (MOM). The numerical model with its equations and algorithms is documented by Bryan [9] and in the above study. The boundary conditions at the sea surface are given in Appendix A. Solid boundaries are non-slip and insulating for temperature and salinity. The bottom is free sleep and insulating. An important difference from the Black Sea model of Stanev et al. ([44] hereafter SRRS) is the parameterization of the internal mixing. We include here a new parameterization of the Bosphorus inflow/plume, based on the results of Stanev et al. [45].

The model resolution is $1 / 4^{\circ}$ in latitude and $1 / 3^{\circ}$ in longitude, and the 24 model depths are at 2.5, 7.5, 12.5, 17.5, $25,35,45,55,65,75,85,105,140,185,240,310,400$, $515,665,870,1145,1470,1820,2125 \mathrm{~m}$. With this resolution we have almost square grid elements in the horizontal. The vertical resolution is substantially increased in comparison to that used by SRRS. The bottom topography for the model (figure 1) is discretized from the UNESCO bathymetric map (kindly provided by the METU-Erdemli, Turkey) with the specific model resolution. The wide and rather shallow shelf area in the northwestern Black Sea is resolved sufficiently by the first eight model levels. 
Mixing and diffusion in the horizontal are parameterized with biharmonic operators. The coefficients are: $A_{h}=K_{h}$ $=0.8 \times 10^{19} \mathrm{~cm}^{4} \mathrm{~s}^{-1}$. More details about the sensitivity of the same model to horizontal diffusion are given by Stanev et al. [45]. The vertical viscosity coefficient is $A_{v}=1.5 \mathrm{~cm}^{2} \mathrm{~s}^{-1}$. The vertical diffusion coefficient is stability dependent, $K_{v}=\frac{a}{N}$, where $N$ is the BruntVaisala frequency, $a=0.004 \mathrm{~cm}^{2} \mathrm{~s}^{-2}[16,23,45]$, giving the motivations to tune $K_{v}$ to the Black Sea stratification). In the surface $30 \mathrm{~m}, K_{\nu}$ decreases linearly from its surface value of $1 \mathrm{~cm}^{2} \mathrm{~s}^{-1}$ to its value at $30 \mathrm{~m}$ calculated from the above formula. This is done to take into account (at least very roughly) the increased diffusion in the mixed layer. The relaxation time scale $1 / \eta$ in equation $\mathrm{A} 3 \mathrm{a}$ is ten days. More details about the subgrid parameterizations and the model sensitivity to $\eta$ are given by Stanev et al. [45] and Rachev and Stanev [36].

We close the model balances at the sea surface by specifying a compensating flux in the Bosphorus Strait. The parameterization of this flux is based on a simple concept for the water balance. The Black Sea exchanges water with the atmosphere, gains fresh water from the river runoff, and the balance is maintained by the exchange through the Bosphorus Strait. We compensate for the fresh water gain at the sea surface by some fresh water removal in the strait. The results of observations or the hydraulic control theory permit the parameterization of this inflow as a function of the water balance at the sea surface. The details are given in Appendix B. The simulated transport and its time variability (see further in text) are filted to the observations $[28,49]$. It is known that the heat deficit at the sea surface is almost compensated by the strait exchange, thus we close the heat balance in the strait, as well.

The convection in the Bosphorus inflow area in the model of SRRS is governed by the standard model physics only. However, with its coarse resolution, the model does not take account of the specific time and length scales, and the Mediterranean plume does not sink deep enough (for more details about the role of the model resolution for the model sinking and entrainment see Stanev $[42,43]$ ). To simulate a realistic convection in the present model, a new routine, parameterizing the plume and the entrainment, is added to the main code. This routine is prepared as a substitute for the convective adjustment; additional details, including the description and implementation in the model, can be found in Appendix $B$ and in the paper by Stanev et al. [45].

\section{FORCING DATA}

\subsection{Some important features in the Black Sea clima- tology}

The Black Sea is located in the northern part of the subtropical latitudes, with its northern extremity in the temperate climatic zone. The atmospheric fields over the sea are affected by the Azore and Siberia centres of high pressure and by the atmospheric patterns over the adjacent areas in Europe and Asia. The main tracks of the winter storms of Mediterranean origin pass over the southern part of the sea, and are directed to the northeast. Depressions originating from the Atlantic ocean cross Romania and Bulgaria and propagate to the east and southeast. The wind is generally cyclonic, with magnitudes usually between 2 and $7 \mathrm{~m} \mathrm{~s}^{-1}$. In $80 \%$ of the cases, the wind speed is below $5 \mathrm{~m} \mathrm{~s}^{-1}$, and exceeds $15 \mathrm{~m} \mathrm{~s}^{-1}$ on about 20 to 40 days each year. In the northern and western Black Sea, the frequency of occurrence of NE, N and NW winds is about $50 \%$. Winds with an eastern component dominate the patterns over the northern coast of the Caucasus. The influence of the Azore anticyclone in the warm part of the year increases the probability of NW, W and SW winds.

The air temperature at the sea surface shows strong spatial variations, particularly in winter. In that season, the penetration of cold air masses from the north is facilitated by the flat land, and negative temperatures are by no means exceptional. The horizontal temperature gradients are about twice as small in summer as in winter. Cloudiness (annual mean value of about $60 \%$ ) has maxima in winter and minima in summer. It has less pronounced gradients in space than the precipitations (300$500 \mathrm{~mm} \mathrm{y}^{-1}$ in the western and north-western part, 750 $800 \mathrm{~mm} \mathrm{y}^{1}$ in the southern part, and $1800-2500 \mathrm{~mm} \mathrm{y}{ }^{\prime}$ in the easternmost Black Sea). The increase in precipitation along the eastern coast is due to the local orography (the coast is normal to the wind direction). Additionally, the proximity of the Caucasus amplifies precipitation.

The Black Sea has a vast catchment area (1 874904 $\mathrm{km}^{2}$ ), which is about 4.5 times larger than the sea surface itself. Due to this unique ratio, the sea is affected indirectly (via river runoff) by the climatic variability over a large area of Europe. The river discharge (about 
$350 \mathrm{~km}^{3} \mathrm{y}^{-1}$ ) is one of the most accurately estimated components of the Black Sea fresh water balance. However, large differences can be found in the existing estimates for evaporation and precipitation. We refer here to the estimates of Unluata et al. [49], giving $300 \mathrm{~km}^{3} \mathrm{y}^{-1}$ for precipitation and $350 \mathrm{~km}^{3} \mathrm{y}^{-1}$ for evaporation. The difference between precipitation and river runoff, on one hand, and evaporation, on the other $\left(300 \mathrm{~km}^{3} \mathrm{y}^{-1}\right)$ is equal to the barotropic transport in the Bosphorus Strait.

\subsection{Data sources for the present study}

The main data sources are the heat flux components of Makerov [26] and the data for precipitation and wind given in the climatic handbook of the Black Sca, cdited by Sorkina [41]. The data of Makerov [26] are calculated from 60000 ship observations, taken after 1910. The computational method is based on the classical Budyko [10] approach, i.e. monthly mean atmospheric fields are first produced, and then the fluxes are calculated. The climatic data of Sorkina [41] originate from coastal measurements (after 1881) and ship measurements (after 1891) for temperature, humidity, wind magnitude and direction, precipitation, and clouds. A total of 67000 open-sea measurements are used. The number of measurements is less for humidity (45000) and precipitation (52000). From these data, we compute the climatic model forcing data set (C-data, see table $I$ ) in the model grid. The climatic data for the river runoff of Altman and Kumish [2] are used to complete the fresh water balance.
The second data source is the climatic data set kindly provided by Yu Golubev from the Sevastopol Marine Data Information Association (briefly S-data set, $\mathrm{S}$ refers to Sevastopol, see table I). Part of the S-data have been reported by Altman et al. [1] and in the Black Sea volume of the "Hydrometeorology and Hydrochemistry of the USSR Seas" ([40], hereafter BSHH). One important difference between the $\mathrm{C}$ - and $\mathrm{S}$-data is that measurements from the last twenty years are added to the S-data. It is noteworthy that the data for the coastal areas of Bulgaria and Turkey in both data sets are insufficient to obtain reliable estimates.

Atmospheric analyses provide an alternative data source, which can be used to prepare model forcing functions. However, detailed testing is needed before applying these data as model boundary conditions ([45] SRRS). The forcing in these studies uses the bulk formulae (Appendix A), atmospheric data, and model simulated Sea Surface Temperature (SST). The atmospheric data (wind, air temperature and relative humidity) were derived from the US National Meteorological Center (NMC.) 1000 mbar analysis for the period 1980-1986 and were interpolated on to the grid. Comparison of the climate derived from the NMC data with the observations reveals some inconsistencies. The patterns of the NMC wind curl (figure $1 b$ of SRRS) show that large areas in the western Black Sea are dominated by anticyclonic winds, which does not match the climatic data of Rachev et al. [35]. The oceanic response to this forcing, illustrated by the annual mean total transport stream function (figure $4 c$ of SRRS),

Table I. Forcing data for the Black Sea.

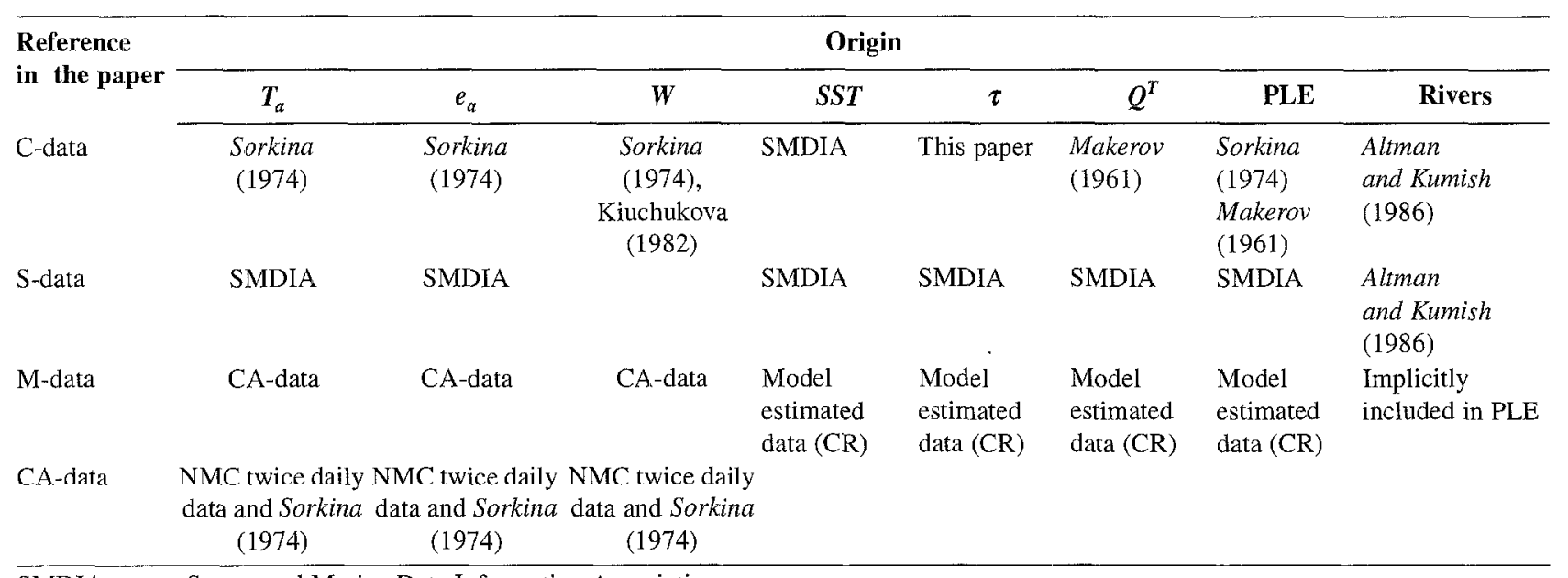

SMDIA means Sevastopol Marine Data Information Association

See in the text for the other notations 
shows very small values of the annual means, compared to the variances. This model peculiarity deviates strongly from what is known for the circulation in the Black Sea. The NMC data give higher annual mean temperatures (about $2{ }^{\circ} \mathrm{C}$ ) and lower humidity (about $10 \%$ ) than the climatic data. The discrepancies could be due to measurement problems and data processing when calculating cli- matic data, but also to the analysis procedure on the scale of a small inland basin and to the coarse resolution. It is shown by Staneva et al. [46] that the climate of the NMC data gives very smooth pattems.

Bearing in mind the importance of short periodic oscillations in atmospheric forcing for water mass formation (SRRS), it appears reasonable not to distegard the whole


Figure 3. Annual mean forcing functions. Wind stress and wind-stress curl in: a) C-data, b) S-data. The contour interval for wind-stress curl is $5 \times 10^{-9} \mathrm{~Pa} \mathrm{~m}^{-1}$. Dash lines correspond to negative values, full lines to positive values; c) air temperature $\left.\left({ }^{\circ} \mathrm{C}\right), \mathrm{C}-\mathrm{data} ; \mathrm{d}\right)$ air temperature, $\left({ }^{\circ} \mathrm{C}\right)$, $\mathrm{S}$-data; e) vapour pressure (hPa), C-data; f) vapour pressure, (hPa), S-data. 
information in the atmospheric analysis data, but to combine the seasonal signal from the climatic data sets (this signal is much more reliable than that of the NMC climate) with the high frequency signal of the NMC analysis data. In the new atmospheric datia set, we replace the low-frequency signal in the NMC data by the same signal derived from the C-data. We refer to this data set as to Climate-Analysis (CA) data. Some response effects from
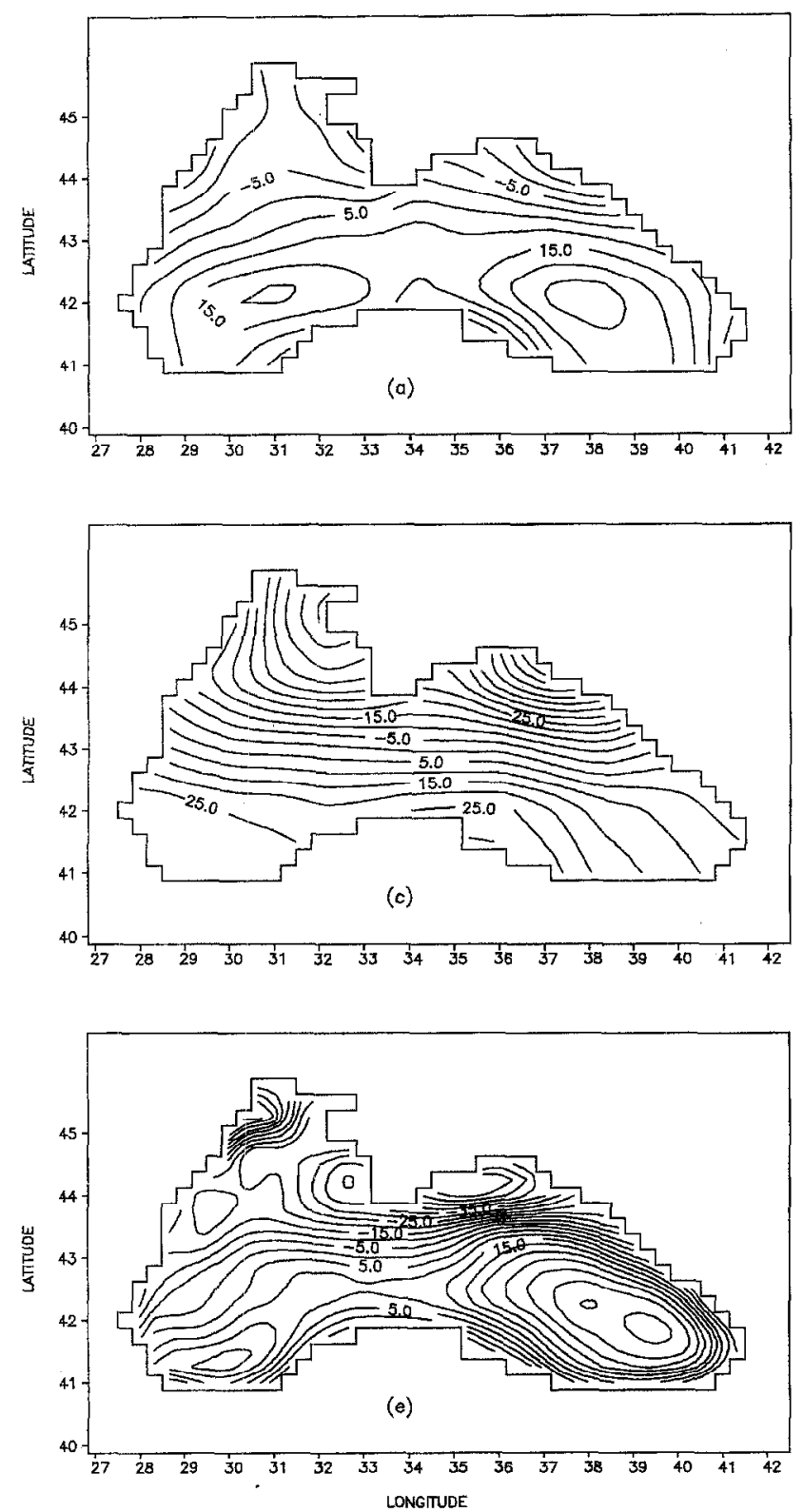

using the CA-data to force the Black Sea model with the same set-up, as in the present paper, are studied by Stanev et al. [45].

The third type of flux data, used in the present study, originate from model estimates. It is well known that models forced with relaxation boundary conditions can be used to compute heal and salt fluxes at the sea surface [8]. In the ocean simulations, these fluxes could replace
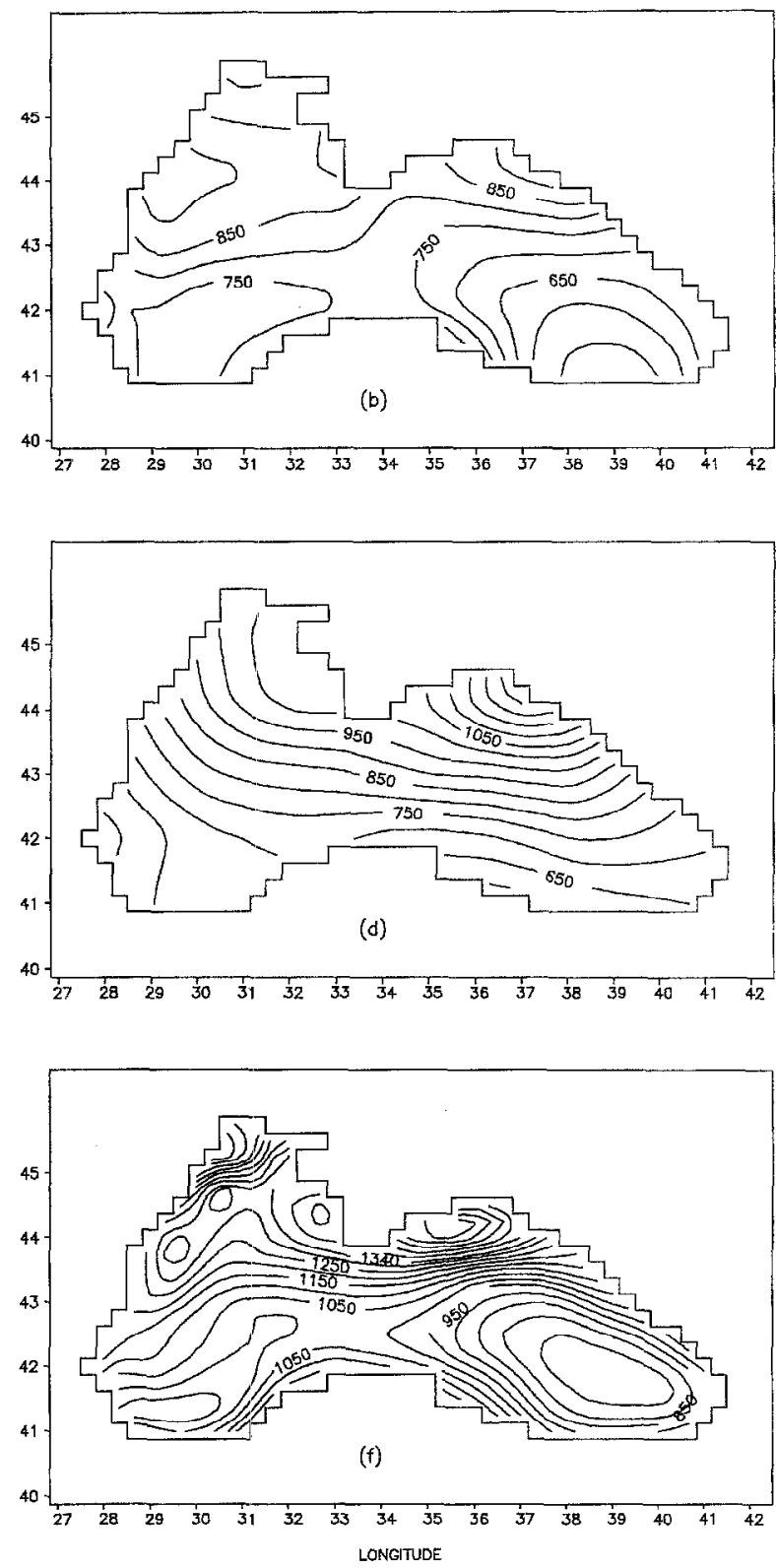

Figure 4. Annual mean total heat flux $\left(\mathrm{W} \mathrm{m}^{-2}\right)$ and evaporation (mm year $\left.{ }^{-1}\right)$; a) heat flux, C-dlata; c) heat flux, S-data; e) heat flux, M-data; b) evaporation, C-data; d) evaporation, S-data; f) evaporation, M-data (see table I). 
data lacking from observations or insufficiently accurate. It is desirable to compare these synthetic data with estimates from observations (when available), as well as to study the differences in the ocean responses. In the following we describe the Control Run (CR), which is used to produce such diagnostic data. We initialize the numerical model with annual mean climate data and start the integration from rest. The SSS is computed at every time step from monthly mean climatic data, using linear interpolation (figure $2 a$ shows the climatological SSS). Then we calculate the restoring term in equation $\mathrm{A} 3 \mathrm{~b}$. The mechanical forcing and the forcing for the equation of temperature are calculated in the model interactively (see Appendix A). To do this, we use model SST, CA-data for atmospheric temperature, relative humidity, and winds, and bulk aerodynamic formulae. The model output consists, along with the standard MOM output, of monthly means for the model forcing, i.e. heat flux (computed from the equations A 4-A 6) and fresh water flux at the sea surface (computed from equation A $3 b$ ). As shown by Staneva et al. [46], the simulated heat balance is consistent with the estimates of other authors, and in some aspects even better.

We follow the above idea in the present study, and prepare monthly mean heat and fresh water fluxes in the format of those produced using observation data only. This data set, Model (M)-data, after forty years of integration of the CR, is analysed further in this section, and used in the following section to force numerical simulations with heat and fresh water fluxes.

\subsection{Wind stress}

We produced a new wind stress data set using a main data source [41] which gives the wind-speed frequency distribution for each month in six ranges for wind magnitude and in eight sectors for the direction. These data are prepared from ship observations, and are given for 16 coastal stations and 28 one-degree squares in the open sea. We recall here that the wind stress values of Rachev et al. [35] are based on the same data source, but that the accuracy is poor in some areas, where the data coverage is bad. Therefore, wind speed frequency data from ten Bulgarian coastal stations [22] and monthly mean data for wind magnitudes (available for the whole sea, [41]) were added. As in the paper of Rachev et al. [35], we use quadratic bulk formula (A 7) to calculate wind stress, but the drag coefficient now is stability-dependent [20]. Test experiments in the areas with good data coverage are car- ried out, with the elimination of part of the wind-rose data and the substitution of wind magnitudes only. The errors resulting from this substitution are smaller than those resulting from extrapolating the data. Thus, we tuned the computational procedure to increase the weight of the monthly mean data for wind magnitude when computing the wind stress in the southern Black Sca. The strength of this tuning decreases to the north, where the amount of wind-rose data is sufficient for correct estimates. In regions with good data coverage, the weight of the wind magnitude from monthly mean data is negligible. This procedure does not affect the direction of wind stress.

We found the wind stress patterns to be strongly affected by the coastal station data, because the wind direction over the land differs from that over the sea. Since there are enough data in the open sea, off the coast of the former Soviet Union, we disregard the coastal data of Sorkina [41]. This is another difference from the computational procedure of Rachev et al. [35]. The rest is essentially the same.

The annual mean wind-stress patterns (figure $3 a$ ) show some similarities with most of the monthly mean windstress fields (not shown here), e.g. northerly winds in the western basin and pronounced anticlockwise curl in the eastern one. However, the annual mean field is much smoother than the monthly mean ones, particularly in the western part of the sea. The wind pattern in the eastern Black Sea does not change qualitatively throughout the year, thus the time averaging there does not tend to decrease substantially the annual mean values. The main difference between the wind-stress patterns in the $C$ and $S$-data (figure $3 a$ and figure $3 b$ ) is that the S-data show smaller magnitudes in the eastern part of the Black Sea than the C-data (the cyclonic circulation of the Causcasian coast is about three times weaker in the S-data). The difference between the wind-stress magnitudes is less pronounced in the western Black Sea, but the differences in the wind directions are larger there.

The wind-stress curl is cyclonic in the two data sets, but smoother in the S-data (figure $3 b$ ). The area with negative values along the Bulgarian coast is smaller in the $\mathrm{S}$-data than that in the C-data. In the north-eastern part of the sea, the wind-stress curl in the S-data is more than two times smaller than in the C-data, and its maximum is shifted towards the Azov Sea. The climate of the CA-data is very close to that of the C-data (see further in texi), thus we do not discuss the CA-data here. 


\subsection{Horizontal patterns of the forcing functions}

We analyse the horizontal patterns of the three forcing data sets: M-, C-, and S-data, starting with the annual mean temperature and vapour pressure derived from observations (figure $3 c, f$ ). The areas of increased temperature in the south-western and south-eastern Black Sea almost coincide in the two data sets (figure $3 c, d$ ). The temperature decreases from the north-western shelf (12$\left.12.5^{\circ} \mathrm{C}\right)$ to the south-east $\left(14-15^{\circ} \mathrm{C}\right)$. The gradients are mostly due to the contribution of thermal contrasts in the cold part of the year (about $7^{\circ} \mathrm{C}$ throughout the sea). The temperature patterns are rather homogeneous in summer (the maximum differences in the monthly means are about $2{ }^{\circ} \mathrm{C}$ throughout the sea). The pattern in figure $3 c$ is very close to the one in BSHH (figure 3.2, part 1 in this book).

The annual mean vapour pressure patterns (figure $3 e$ and 3f) are qualitatively similar to those of temperature, since the evaporation increases with increased contrast between air and sea-surface temperature. Monthly mean values, higher than $20 \mathrm{hPa}$, are observed in the eastern Black Sea from June to September. The lowest values (of about 6$7 \mathrm{hPa}$ ) are located in the north-western region, from December to February. The annual mean vapour pressure in the C-data is slightly higher than in the S-data, but the main difference between the two data sets is in the shape of the isolines. They have slightly different slopes against the coast in the western and southern Black Sea. This correlates with the same difference in the temperature patterns (compare figure $3 e, f$ with figure $3 c, d$ ).

The heat fluxes, corresponding to C-data (figure $4 a$ ), are computed in 1-degree squares, using bulk aerodynamic formulae [26]. Later, Shahanova and Shutova [39] compared these estimates with heat flux measurements. They showed that a good correlation exists between the two types of data in summer, but found some deficiencies of the estimates in autumn. Further development of these studies $[14,17]$ was based on new parameterizations of the heat exchange and resulted in producing the $\mathrm{C}$-data. The computational procedure is described in BSHH. Our figure $4 c$ practically coincides with figure 1.12, part 2 of BSHH. The data used by Golubeva to compute the heat fluxes originate from the meteorological data of Sorkina [41] and the SST data of Altman et al. [1]. The difference between the SST, used by Makerov and Golubeva, is perhaps the main reason for the differences between the corresponding heat fluxes (figure $4 a$ and $4 c$ ).

The net heat flux is $3.8 \mathrm{~W} \mathrm{~m}^{2}$ in the C-data and zero in the S-data. The areas of strongest cooling do not coincide on the shelf in Makerov's estimates (east of the Romanian coast) and in the estimates of Golubeva (west of the Crimea). The second cooling zone (in the north-eastern Black Sea) shows qualitatively similar patterns in the two data sets. Another important difference between the $\mathrm{C}$ and S-data is illustrated in the southern Black Sea, where the patterns in figure $4 c$ show zonal isolines, whereas two centres of increased heating are well pronounced in figure $4 a$. The last seems morc consistent with the model estimates (figure $4 e$ ), which are obtained independently. However, the gradients are much larger in the M-data than in the C-data.

There is a strong similarity between the evaporation patterns corresponding to the three data sets (figure $4 b, d, f$ ) and the heat flux patterns (figure $4 a, c, e$ ). Thus, we conclude that the latent heat flux dominates the net heat flux pattern. The only qualitative agreement betwecn figure $4 b$ and figure $4 d$ is that the evaporation increases to the north, and the maxima could be found in the latitudinal band of $44^{\circ}-45^{\circ} \mathrm{N}$. As will be shown further in this paper, despite the large deviations between the two patterns, the basin averaged values are not too different.

Measurements of precipitation are very sparse in the Black Sea. The only available data are the numbers of days with precipitation per month, originating from ship observations. The existing open-sea data are adjusted by Sorkina [41] and in the BSHH to the estimates from the coastal stations. Indirect information (e.g. the Black Sea water balance) is also used as an additional constraint. As indicated by Altman in the BSHH, the most reliable data are those of Sorkina [41]. These data (figure 5a) are updated in the BSHH for the last 15 years (figure $5 b$ ), but the update resulted in minor differences. The two data sets clearly show the main peculiarity of Black Sea precipitation: extremely high values in the eastern area. The basin mean values - $540 \mathrm{~mm} \mathrm{y}^{-1}$ in the C-data and $575 \mathrm{~mm} \mathrm{y}^{-1}$ in the S-data - are smaller than the estimate of Unluata et al. [49], $714 \mathrm{~mm} \mathrm{y}^{-1}$.

\subsection{Time variability}

Variability in forcing functions has an important role for the model simulated variability; therefore we analyse below the basin-averaged seasonal cycle of the three forcing data sets: M-, C-, and S-data. This is also motivated by the large uncertainty concerning the temporal variability of heat and fresh water flux at the sea surface. Here, we show air temperature, SST, SSS, saturation vapour pressure, wind-stress curl and wind-stress magnitude 

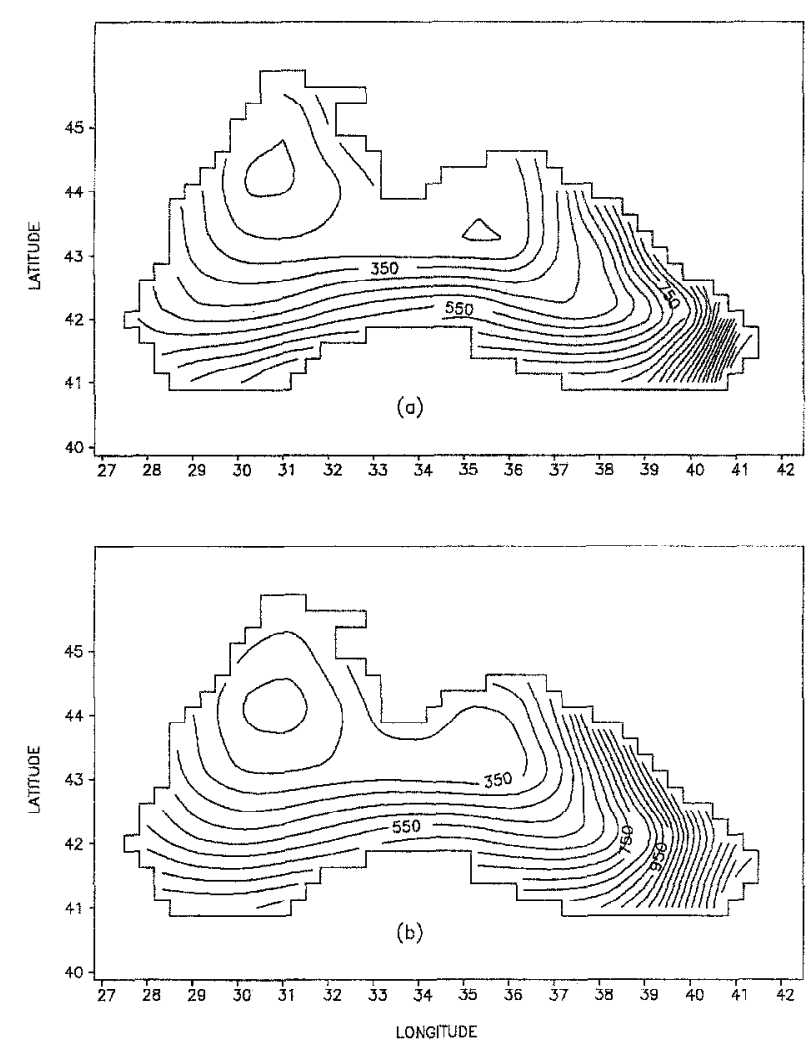

Figure 5. Annual mean precipitation ( $\left.\mathrm{mm} \mathrm{year}^{-1}\right)$. a) C-data; b) S- data.

(figure 6), as well as the heat and water balance (figure 7). To demonstrate some drawbacks of the NMC climate in the Black Sea, we present the corresponding curves, as well. The differences between the NMC climate and that of the $\mathrm{C}$ - and $\mathrm{S}$-data justifies the motivation to produce the CA-data.

The seasonal cycle in the air temperature (figure 6a) almost coincides in the $\mathrm{C}$ and $\mathrm{S}$-data, but the temperature in the NMC data is about $2{ }^{\circ} \mathrm{C}$ higher. The differences in the vapour pressure are even larger, also between the climatic data sets, (figure $6 b$ ). The winter values almost coincide in the $\mathrm{C}$ - and $\mathrm{S}$-data, but the $\mathrm{S}$-data give lower values (about $2 \mathrm{hPa}$ ) in summer. This difference reaches $4 \mathrm{hPa}$ in the NMC dala.

The seasonal variability of the SSS shows a negative correlation with the SST (figure 6c). In the cold part of the year, both fields depend on evaporation, which tends to decrease the SST and to increase the SSS. However, the phase lag in spring-summer period does not support this mechanism of formation of temperature/salinity anomalies. During this period, the warming tends to increase
SST, whereas increased river discharge tends to decrease the SSS. Thus, the phase difference is due to the time lag between the river discharge and heating from the atmosphere.

The large differences between the horizontal patterns of the wind-stress curl in the C- and S-data (figure $3 a, b$ ) almost cancel in the area-averaged values, and the seasonal signal looks similar (figure $6 d$ ). The wind-stress curl is cyclonic during the whole year, with a maximum in January and a minimum in April-May. This type of variability contributes to the increase in the cyclonic circulation in winter $[6,15,43]$. The seasonal variability in the NMC climate does not show any similarity with that of the C- and S-data. Thus, we conclude that the atmospheric analysis data should be used very carefully to forcing numerical models, particularly in the areas of small inland basins.

The Sverdrup balance is not the dominating one in the dynamics of small inland basins [36], and is unlikely to describe correctly the mechanical forcing by analysing the wind-stress curl only. Therefore we show in figure $6 e$ the wind-stress magnitude corresponding to the three data sets. The C-data give larger amplitudes than the S-data and more than $50 \%$ larger annual mean magnitude. However, in contrast with the wind-stress curl, we have a good qualitative agreement between the three data sets: an increase of the wind magnitude in winter, a secondary increase in summer, and a decrease in spring and autumn. It is noteworthy that the NMC wind even exceeds that of the S-data. The relatively good correlation between the wind stress magnitude of the NMC-data and of the climatic data, and the poor correlation between the corresponding curls (figure $6 d$ ) is a consequence of the coarse resolution of the atmospheric analysis data.

The seasonal variability of the Black Sea thermohaline forcing, together with the estimates from the numerical model (M-data), are shown in figure 7. The estimates based on observations (C- and S-data, dash lines in figure 7 a) show very small differences. The most important one is the time lag between the summer maxima, which is mainly due to the time lag in the evaporation heat. The amplitude of the numerically derived curve (the full line in figure $7 a$ ) is slightly larger than those resulting from the observations. Nevertheless, the agreement is good enough to conclude that the numerical model is sufficiently tuned to simulate the seasonal variability correctly. The fresh water balance (figure $7 b$ ) has almost the same phase in the three data sets, but different amplitudes. The model-estimated fresh water gain is about 


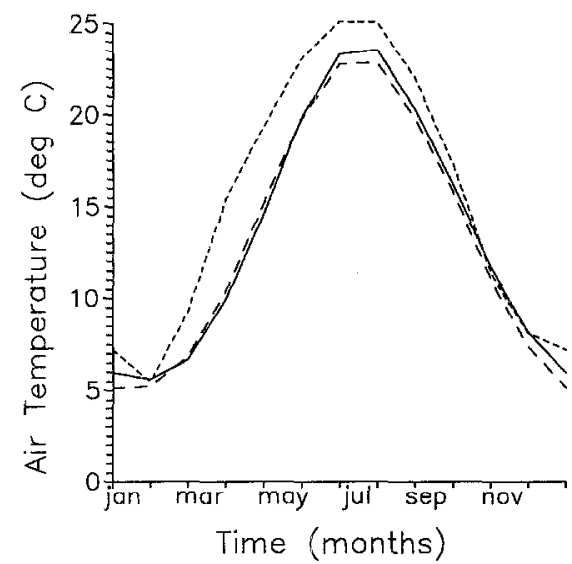

(a)

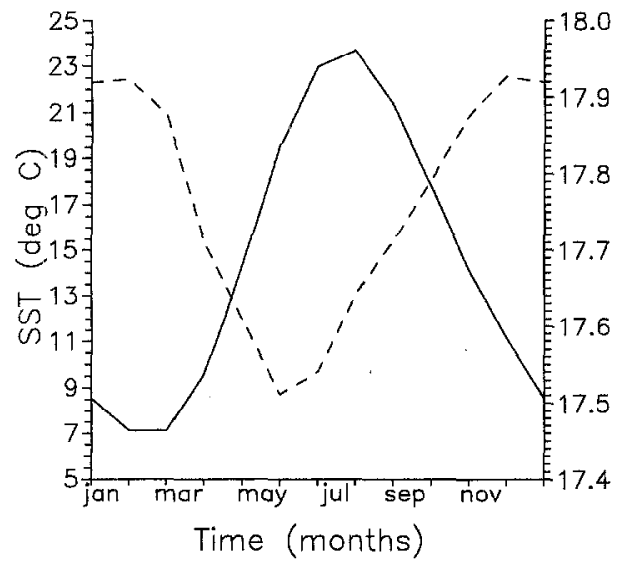

(c)

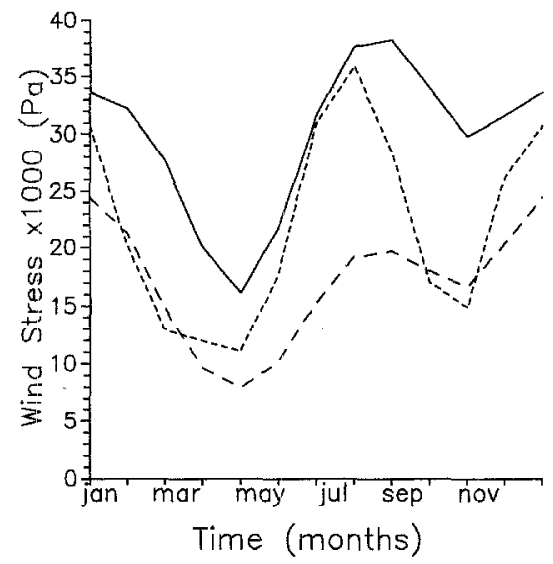

(e)

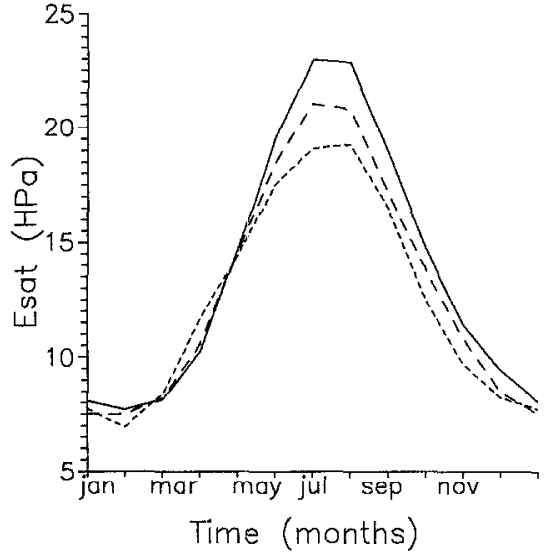

(b)

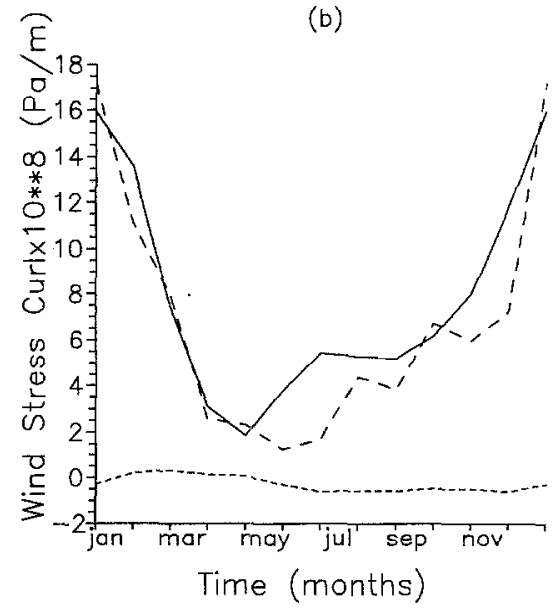

(d)
- C-data

- - S-dato

.....-- NMC-data

Figure 6. Basin-averaged forcing functions: a) air temperature; b) saturation vapour pressure; c) SST-full line, and SSS-dash line; d) wind stress curl; e) wind-stress magnitude. The legend gives the correspondence between different lines and data sets. 
$300 \mathrm{~km} \mathrm{y}^{-1}$. This number practically coincides with that estimated by Unluata et al. [49]. We have lower values in the $\mathrm{C}$ - and S-data (182 and $215 \mathrm{~km}^{3} \mathrm{y}^{-1}$, correspondingly), which is in better agreement with the older estimates of Altman and Kumish [2]. The fresh water gain estimated by the model (the full line in figure $7 b$ ) is dominated by pronounced seasonal changes, showing the largest fresh water flux in spring-summer. The negative values (from August to October) correlate with the increase in evaporation in this season and with the decrease in the fresh water flux. The amplitude of the undercurrent, corresponding to the M-data (asterisk line in figure $7 b$, see also Appendix $\mathrm{B}$ ), is about ten times smaller than that of the sea surface fresh water flux. It decreases to about $7200 \mathrm{~m}^{3} \mathrm{~s}^{-1}$, shortly after the maximum in the fresh water flux is reached, and tends to double in fall, when the fresh water flux reaches minimum. The variability of the undercurrent correlates qualitatively with the estimates of Bogdanova [7] and Simonov and Altman [40].

We stress here one peculiarity of the M-data: the comparison between figure $6 c$ and figure $7 b$ shows a time lag between the period of minimum salinity (May-June) and the period of maximum fresh water flux (April-May). This agrees with the concept that the SSS inversely follows (with some time lag) the river discharge. However, this simulation is made without explicit river forcing.

\section{MODEL RESPONSE}

\subsection{Model experiments}

The model is integrated with flux boundary conditions (equation A 3a), using the simulation data from the CR as initial data. We force the first experiment with the Modelderived Forcing functions (MF-experiment, see table I and table II). The C-data is used to force the second experiment ( $\mathrm{CF}$ experiment) and the S-data is used to force the third experiment (SF experiment). In the forth experiment, we combine the mechanical forcing from the $\mathrm{C}$-data and the thermohaline forcing from the S-data (CSF experiment). The heat flux, fresh water flux and wind stress at the sea surface are interpolated at each time step from the monthly mean data. River runoff is not explicitly included in the MF experiment, whereas in the $\mathrm{CF}, \mathrm{SF}$, and CSF experiments it is added to the fresh water balance at the sea surface in ten locations, corresponding to the river mouths of the main Black Sea
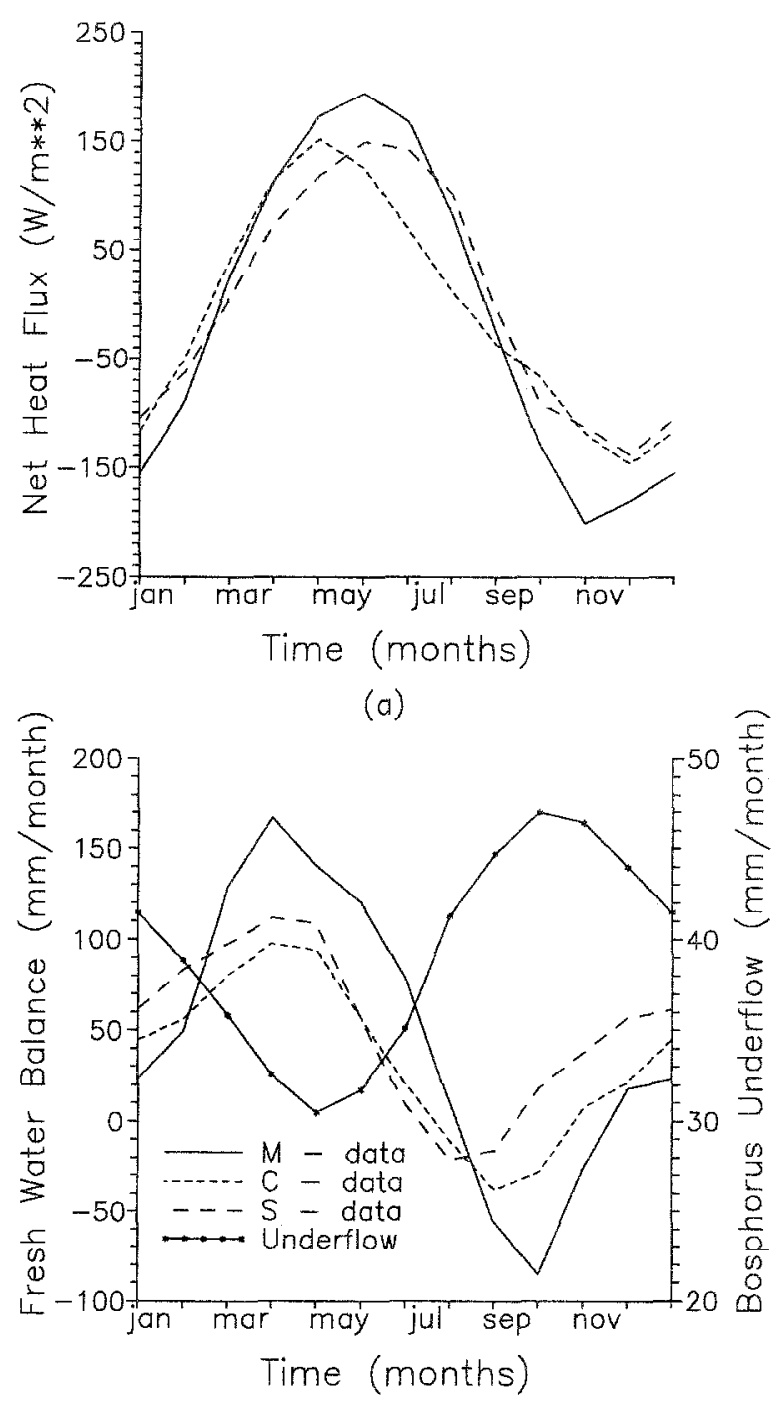

(b)

Figure 7. Components of the heat and water balance. The legend gives the correspondence between different lines and data sets. a) net heat flux; b) basin-averaged fresh water balance. The underflow simulated in the Strait of Bosphorus, corresponding to the fresh water balance in the M-data, is recalculated in the same units as the fresh water flux at sea surface, and plotted with the asterisk line.

rivers. The four experiments with their forcings are summarized in table II. We parameterize the salinity flux by equation (A 3a). This corresponds to the virtual salinity flux, according to the nomenclature of Huang [21].

The integration is carried out until a quasi-periodic solution with negligible trend is reached. The trends do exist in the beginning of the integration, since the initial data 
Table II. Model experiments and their forcing.

\begin{tabular}{lccc}
\hline \multirow{2}{*}{ Reference } & \multicolumn{3}{c}{ Forcing data } \\
\cline { 2 - 4 } & $\tau$ & $Q^{T}$ & $Q^{S}$ \\
\cline { 2 - 4 } MF & C-data & M-data & M-data \\
CF & C-data & C-data & C-data \\
SF & S-data & S-data & S-data \\
CSR & C-data & S-data & S-data \\
\hline
\end{tabular}

are not adjusted to the forcing data in the CF, SF and CSF experiments (as this is the case in the MF experiment). The small trend, which also occurs in the MF experiment, results from the substitution of the high frequency forcing in the CR by smooth (with seasonal variations only) forcing in the M-data. This proves that the MF experiment and the CR are not forced identically (for more details on the "identical" forcing in the restoring and mixed boundary condition experiments we refer to Power and Kleeman [34]). To compensate for the insufficient time resolution in the forcing functions (12 months) we increase the contrast of the virtual salinity flux in space by tuning the constant $S_{0}$, so that the model trend remains small. The motivation for this "amplification" in the signal can be found in the work of Gulev [19], Oberhuber [27], and Cai et al. [13].

Another difference between the MF experiment and the $\mathrm{CR}$ is that we force the MF-experiment with wind stress from the C-data, whereas wind stress in the CR is computed interactively every time step. Thus, the wind stress is dependent not only on the meteorological data, but also on the model-simulated SST. In order not to create too large a variety of different forcing functions, we do not discuss here experiments forced by model data for the wind-stress. This is justified by the comparison between the C-data and the similar data set produced by the model. The difference is not substantial in the monthly means.

The simulations showed that the model is very sensitive to the net fresh water balance. However its magnitude is not well known from observations. In order not to include additional uncertainties, we reduce the fluxes in all experiments to have equal basin mean values of $300 \mathrm{~km}^{3} \mathrm{y}^{-1}$. We proceed in a similar fashion for the thermal forcing. The annual mean net value ranges from $-2.7 \mathrm{~W} \mathrm{~m}^{-2}$ in the $\mathrm{M}$ data to $3.85 \mathrm{~W} \mathrm{~m}^{-2}$ in the C-data, which is a small value, compared to the amplitude of the oscillations. Thus, we reduce the net heat flux in all experiments to $-0.6 \mathrm{~W} \mathrm{~m}^{2}$. This value gives the best correlation between model and observation data.
Though we take some measures to reduce the trends, the deviations from the initial data are clearly seen in figure 8 . The vertical salinity gradient is slightly larger between the sea surface and $250 \mathrm{~m}$ in the CF and SF experiments, compared to that in the MF experintent. The trends in the temperature are more pronounced than those in the salinity. The MF experiment gives warmer SST and cooler CIL than the rest of the experiments. The CIL in the $\mathrm{CF}$ experiment is very shallow, and the content of

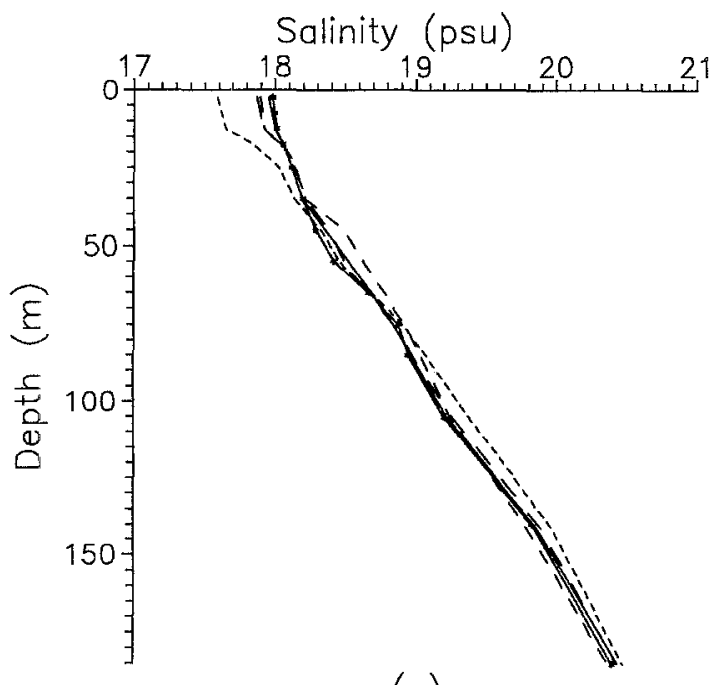

(a)

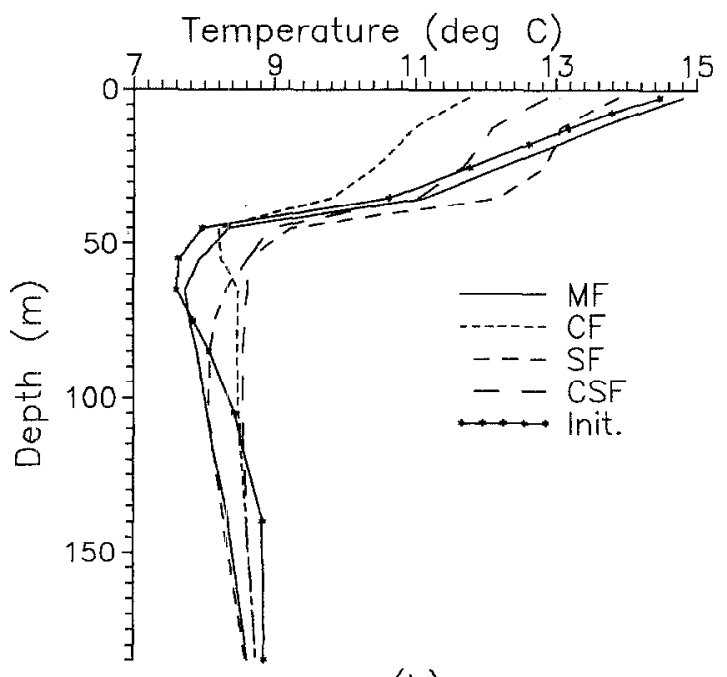

(b)

Figure 8. Basin-averaged annual mean vertical profiles for: a) salinity; b) temperature. The different lines, specified in the legend, correspond to the experiments listed in table II. The asterisk line corresponds to the initial data. 
cold water is much less than in the remainder of the simulations. The results in the CSF experiment are no better, where the CIL practically disappears. In the SF experiment, this layer deepens considerably, and the cold water content decreases strongly, compared to the simulations in the MF experiment. Comparisons with the initial data, or with data from other sources (c.g. figure 2.16, part 2 of BSHH) show that the MF experiment simulates very adequately the vertical stratification.

\subsection{Time variability}

The winter intensification of the circulation is explained by Filippov [15], Blatov et al. [6] and Stanev [43] as an oceanic response to wind forcing. However, there are other possible explanations, relating the intensity of the circulation to the mesoscale eddy activity [36]. The variability in the fresh water forcing could also induce seasonal changes $[43,12,30]$. The results of the model simulations might help to explain the relative contribution of these processes.

The basin-averaged kinetic energy (figure $9 a$ ) and the total transport (figure $9 b, c$ ) between the two ends of the meridional sections, shown in figure 1, illustrate the seasonal variability of the circulation. The different lines in the legend of figure 9 correspond to the four experiments listed in table II. We use two mechanical forcing functions, one corresponding to the C-data (MF, CF and CSF experiments), and the other to the S-data (SF experiment). The small differences in the time variability of the wind stress curl (figure $6 d$ ) can hardly be the reason for the large difference between the model responses. However, the time variability in the wind stress magnitude (figure $6 e$ ) gives stronger arguments for expecting that the $\mathrm{C}$ - and $\mathrm{S}$-data would drive the model very differently. The two-modal structure of the seasonal signal, which is well pronounced in the $\mathrm{C}$-data, tends to create a twomodal seasonal variability of the kinetic energy in the CSF experiment (figure $9 a$ ) and in the total transport in the CF experiment (figure $9 b, c$ ). The smaller magnitude in the wind-stress forcing in the S-data (figure $6 e$ ) results in smaller kinetic energy in the SF experiment (1.5-2 times smaller than in the remainder of the experiments). This demonstrates that the model response is extremcly sensitive to differences or errors in the wind forcing, and provides strong arguments and motivations for further improvements in the mechanical forcing.

The winter intensification (illustrated by the maximum in the kinetic energy, figure $9 a$ ) is coherent with the basin-

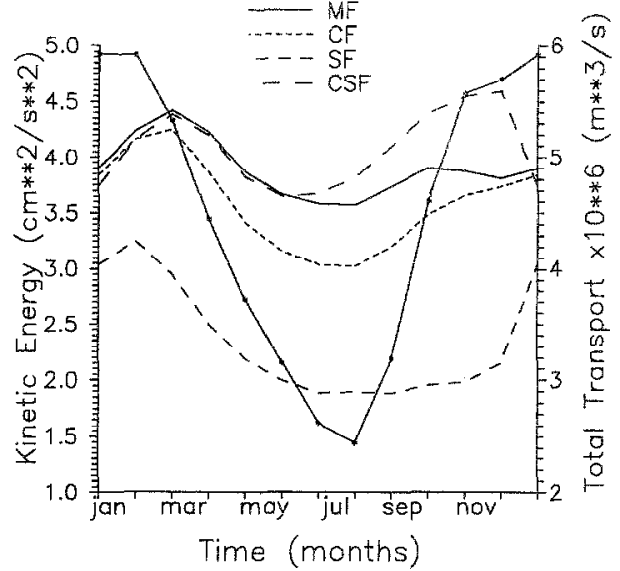

(a)

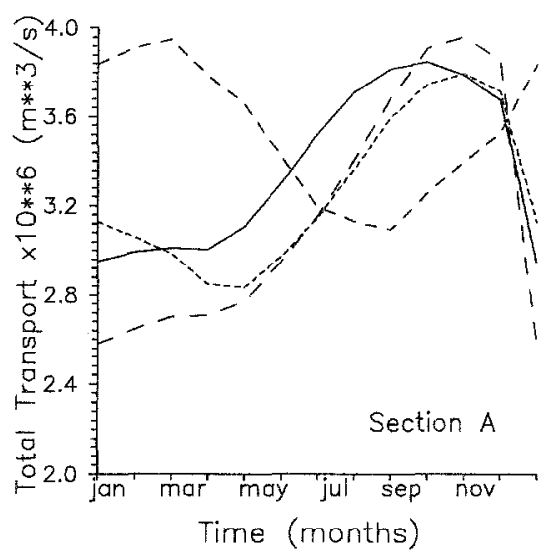

(b)

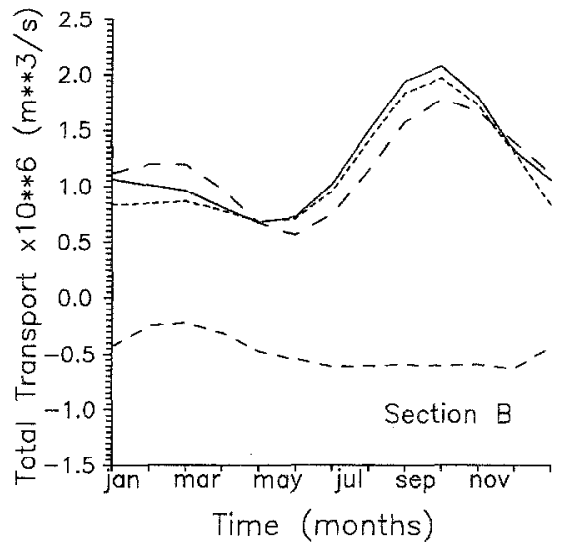

(c)

Figure 9. a) Basin-averaged kinetic energy and total transport simulated in the MF-experiment (asterisk line) along the section $\mathrm{C}$ in figure $1 \mathrm{a}$; b) total transport along the section $\mathrm{A}$ in figure $1 \mathrm{a}$; c) total transport along the section B in figure $1 a$. The different lines, specified in the legend, correspond to the experiments listed in table $I$. 
averaged wind-stress curl (figure $6 d$ ). This intensification, seen by the maximum of the integrated mass transport in the narrow section of the sea (between the Crimea and Turkish coasts, section line $\mathrm{C}$ in figure 1 ), reveals similar coherency. This section line reaches the basin interior, where the transport is small. Thus, it gives an estimate which is representative of the intensity of general circulation. However, the transport changes differently in time and space, and appears to be very sensitive to the changes in the wind magnitude (figure $9 b, c$ ). This could indicate that significant conclusions could be made about the time variability of the circulation intensity induced by mechanical forcing.

The differences between the simulations in the CF and CSF experiments are due to thermohaline forcing (figure 7). The net heat flux in the C- and S-data shows similar variability with slightly different phases (figure 7a). It is unlikely that this forcing is responsible for the differences simulated in the CF and CSF experiments. However, the basin-averaged fresh water flux (figure $7 b$ ) seems to be the candidate to explain the continuous increase in the deviation between the kinetic energy in the two experiments (figure $9 a$ ).

The sensitivity of the oceanic response to buoyancy forcing is very pronounced in the behaviour of total transport in the western Black Sea (compare figure $9 b$ and figure $9 c$ ). In this part of the sea, the biases between the $\mathrm{CF}$ and CSF experiments are largest in January. They constantly decrease until July, when their sign changes. Comparison between figure $9 a$, on the one hand, and figure $9 b, c$, on the other, shows that to characterize the circulation as intense or weak we need more factors. The volume mean kinetic energy only, or the total transports only (particularly if they are estimated along sections, not enough representative for the whole basin) could lead to controversial conclusions. This proves that the variability in the Black Sea is characterised by a significant spatial inhomogeneity.

Finally, we analyse the results of the MF experiment. The curve illustrating the basin averaged kinetic energy (figure 9a) lies between the corresponding curves in the CF and CSF experiments. The distance between the curves indicates that the MF simulation is closer to the $\mathrm{SF}$ one in the first part of the year, but tends towards the $\mathrm{CF}$ simulation in the second part. This is consistent with the seasonal variability of the fresh water flux (figure $7 b$ ), showing smaller difference between the $\mathrm{M}$ and S-thermohaline forcing from February to May and less difference between the M- and C-data in the remainder of the year.
The heat fluxes do not substantially affect the simulated variability (this is known from earlier studies, [12, 43]). Thus, it follows that the model energetics correlates well with the fresh water flux. At the end of the analysis of figure 9 we add that in the MF experiment, the seasonal variations in the transport show better similarity to those in the CSF experiment along section A (figure 1). In the eastern Black Sea, the shapes of the three curves are very similar (figure $9 c$ ). This illustrates again the strong diversity of model responses to thermohaline forcing, both in space and time.

The depth of penetration of the seasonal signal is limited by the strong haline stratification, and the variations of temperature can be observed mainly above the CIL (figure 10). The time lag between the tempcrature at the sea surface and at $55 \mathrm{~m}$ in the warm part of the year is about four months, exactly the same as in the observed data (figure $10 d$ ). This is typical behaviour of the seasonal variability in mid-latitudes, particularly under strong stratification.

The differences between the basin-averaged net heat flux in the different data sets reach $10-15 \%$ of the amplitude of the seasonal signal (figure $7 a$ ). However, the difference between the oceanic response, measured by the maxima in the SST, is about $40 \%$ of the amplitude of the seasonal cycle (the summer maxima in the CF and SF experiments are too low, about $16^{\circ} \mathrm{C}$, which is not realistic). We recall that the wind forcing is the same in the MF and CF experiments, and that the heat flux in the two experiments has the same basin-averaged value. Also, the amplitudes of the heat flux in the M- and C-data are not too different (figure $7 a$ ). However, the surface waters are warmer and the CIL is cooler in the MF experiment (figure 8). Thus, it follows that the response is very sensitive to horizontal gradients in the forcing data (compare figure $4 a$, figure 4e), which is consistent with the results of Cai et al., [13].

The seasonal variability of the basin-averaged salinity (figure 11) correlates with the fresh water flux (figure 7). This correlation is strong at the sea surface, where the salinity minimum is reached about one to two months after the maximum of the fresh water flux (figure $7 b$ ). The time lag between the curves at the sea surface and at $25 \mathrm{~m}$ is about 3-4 months in the warm part of the year. The winter time lag is shorter (1-2 months), and reveals the shorter time scales in this season, due to convection. The time variations below $25 \mathrm{~m}$ result from the vertical displacement of the isohalines, related to the variations in the intensity of the circulation. This is consistent with 


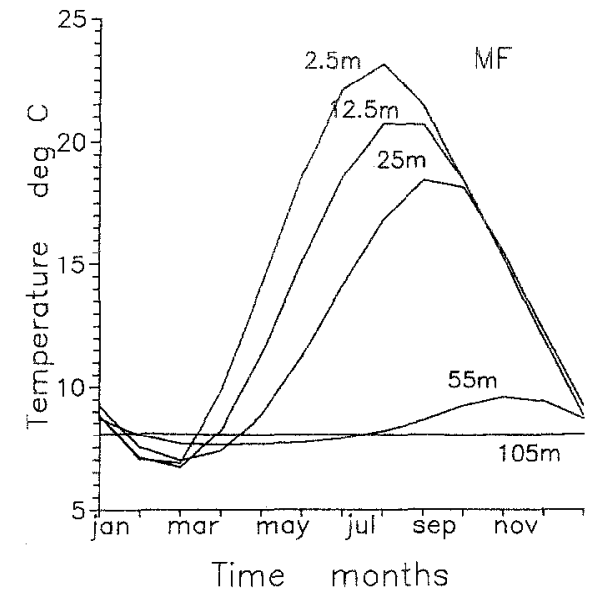

(a)

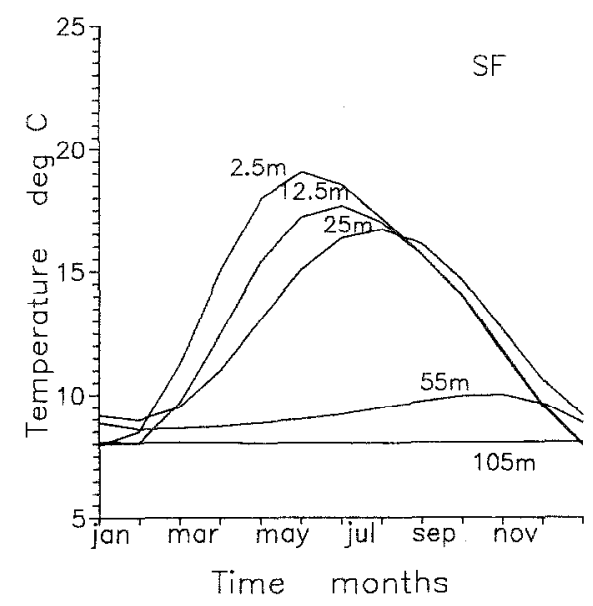

(c)

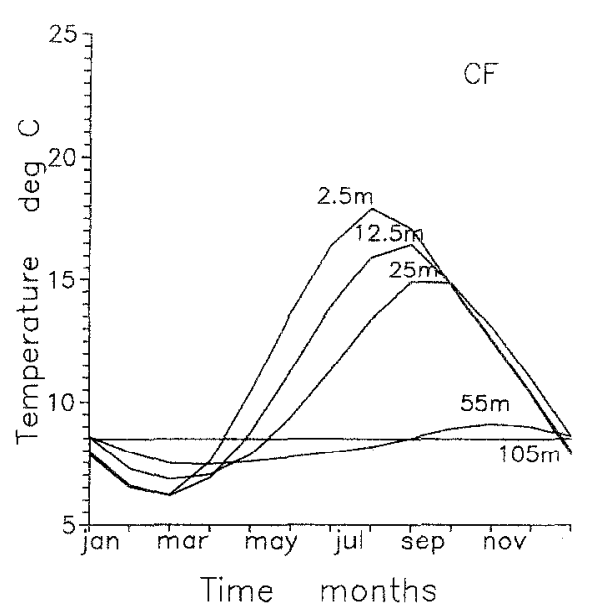

(b)

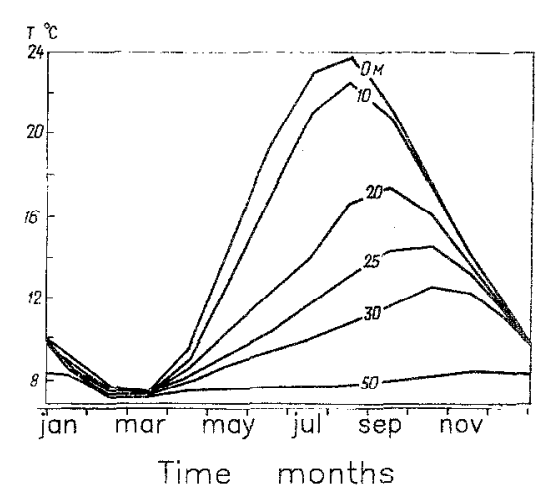

(d)

Figure 10. Basin-averaged temperature in the upper $105 \mathrm{~m}$. a) MF experiment; b) CF experiment; c) SF experiment; d) data from the BSHH.

similar conclusions of Blatov et al. [6] obtained from observations. The model estimates give almost the same magnitudes for the basin-averaged salinity in winter (compare with the observational data, figure $6 c$ ), but slightly larger salinity in summer. The amplitudes of the SSS are smaller in the CF, SF and CSF experiments (not shown here) than in the MF experiment. The differences are largest between the MF experiment, on the one hand, and the SF, or CSF experiment, on the other, which could be expected, bearing in mind the different fresh water forcing (figure $7 b$ ).

\subsection{Analysis of the horizontal patterns}

The patterns of the total transport sirean function simulated under the same mechanical forcing are very similar, thus we analyse only the results of the SF and CSF experiments (figure 12). We have the same thermohaline, but different mechanical forcing in these experiments (table II). The results of the simulations illustrate the sensitivity of the model to differences, or possible errors, in the wind stress. From the patchy wind-stress curl in the C-data (figure $3 a$ ), it is difficult to make a guess about the corresponding patterns of the total transport. If the model dynamics were dominated by the Sverdrup balance, the expected circulation would be cyclonic. This would correspond to figure $6 d$, where the basin-averaged windstress curl is positive throughout the year. However, the weak correlation between the wind-stress curl (figure $6 d$ ) and the total transport across the meridional section lines drawn in figure 1 indicales that the circulation is far from the Sverdrup balance (figure $9 b, c$ ). 


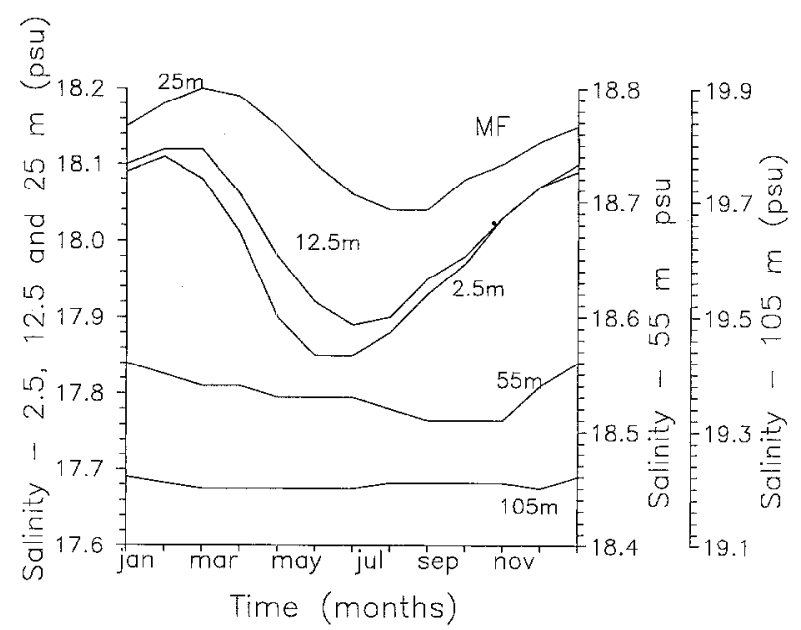

Figure 11. Basin-averaged salinity in the upper $105 \mathrm{~m}, \mathrm{MF}$ experiment.
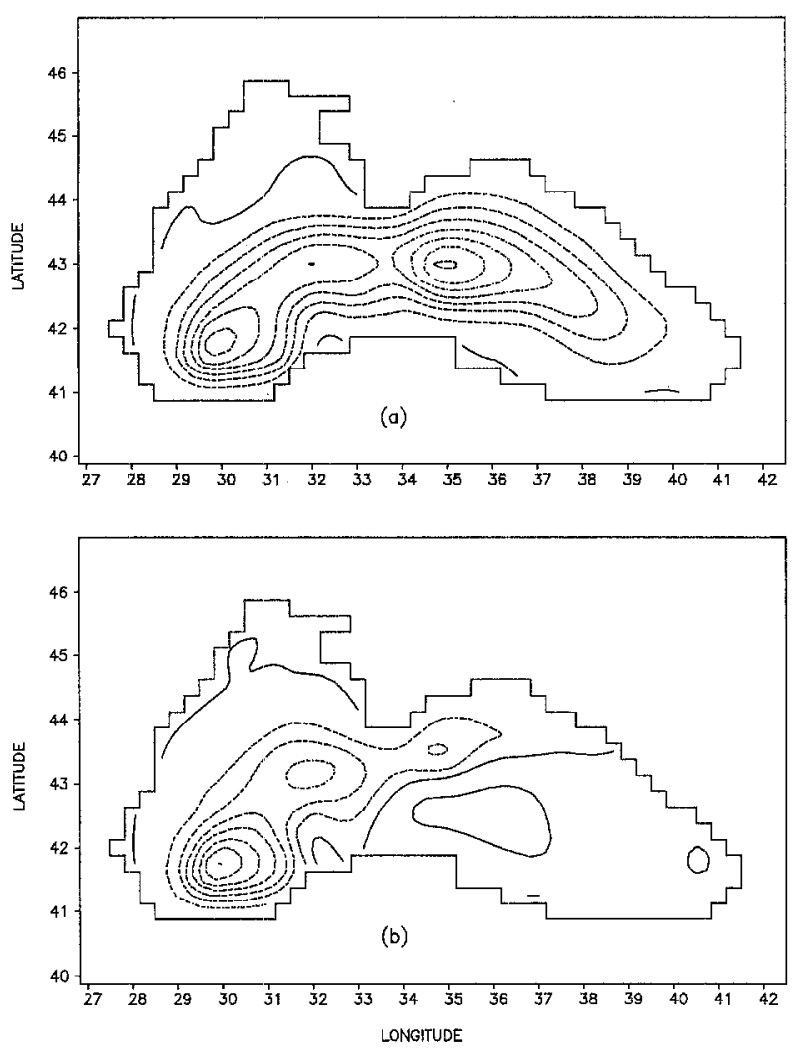

Figure 12. Annual mean total transport stream function, the contour interval is $0.510^{6} \mathrm{~m}^{3} \mathrm{~s}^{-1}$. Dash lines correspond to negative values, full lines to positive values. a) CSF experiment; b) SF experiment.
The CSF experiment shows cyclonic annual mean circulation in the whole basin (figure 12a). This agrees better with the previous estimates $[6,15,43]$ than the simulations in the SF experiment (figure 12b). We explain the more consistent simulations in the CSF experiment as due to the more consistent wind stress in the $\mathrm{C}$-data than in the S-data.

The model simulates large salinity contrasts in the horizontal direction (figure 13). The horizontal patterns are dominated by the dilution in the north-western Black Sea. Owing to the constant salinity value in the expression for the virtual salinity flux basin-wide (equation A 3a), we have abnormally low salinity of about 5 close to the Danube delta in the experiments with explicit rivers (CF, SF, and CSF). Altcrnativcly, we could use the local salinity values in the right hand side of equation $\mathrm{A} 3 \mathrm{a}$, but this would result in "salinity catastrophe" in longer runs, as described by Huang [21]. The MF experiment, in which the fresh water flux is smoother in space than in the S- or C-data, gives more consistent estimates.

The patterns of the SSS do not change substantially throughout the year, and are similar to the annual mean patterns (figure $2 a$ ). In the open sea, salinity increases in winter, which conresponds to the observational data (BSHH). In the north-western Black Sea, the salinity gradient increases in spring, due to the increase in the fresh water flux. The gradients in the shelf area decrease rapidly with increasing depth, and the isolines tend to follow the continental slope in the subsurface layer.

The SST patterns are more sensitive to the seasonal changes in the atmospheric forcing than the salinity ones (figure $13 c, d$ ). The simulated temperatures in the shelf area drop to about $1{ }^{\circ} \mathrm{C}$ in winter. In the easternmost Black Sea, the winter minimum is about $9^{\circ} \mathrm{C}$. The warm tongue along the Caucasian coast indicates the propagation of warm water, originating from the Batumi region. The summer maximum reaches $24^{\circ} \mathrm{C}$ in the eastern basin. The waters in the north-western Black Sea are with about $3{ }^{\circ} \mathrm{C}$ cooler. The small horizontal contrast, simulated in this season, agrees with the climatological data. The largest basin-wide differences in the SST reach $8{ }^{\circ} \mathrm{C}$ in winter, which also supports the observational evidence (BSHH).

\subsection{Analysis of the vertical cross-sections}

We illustrate here the sensitivity of the model Black Sea to the atmospheric forcing by analysing the simulated temperatures and salinities in the upper layer, down to the 

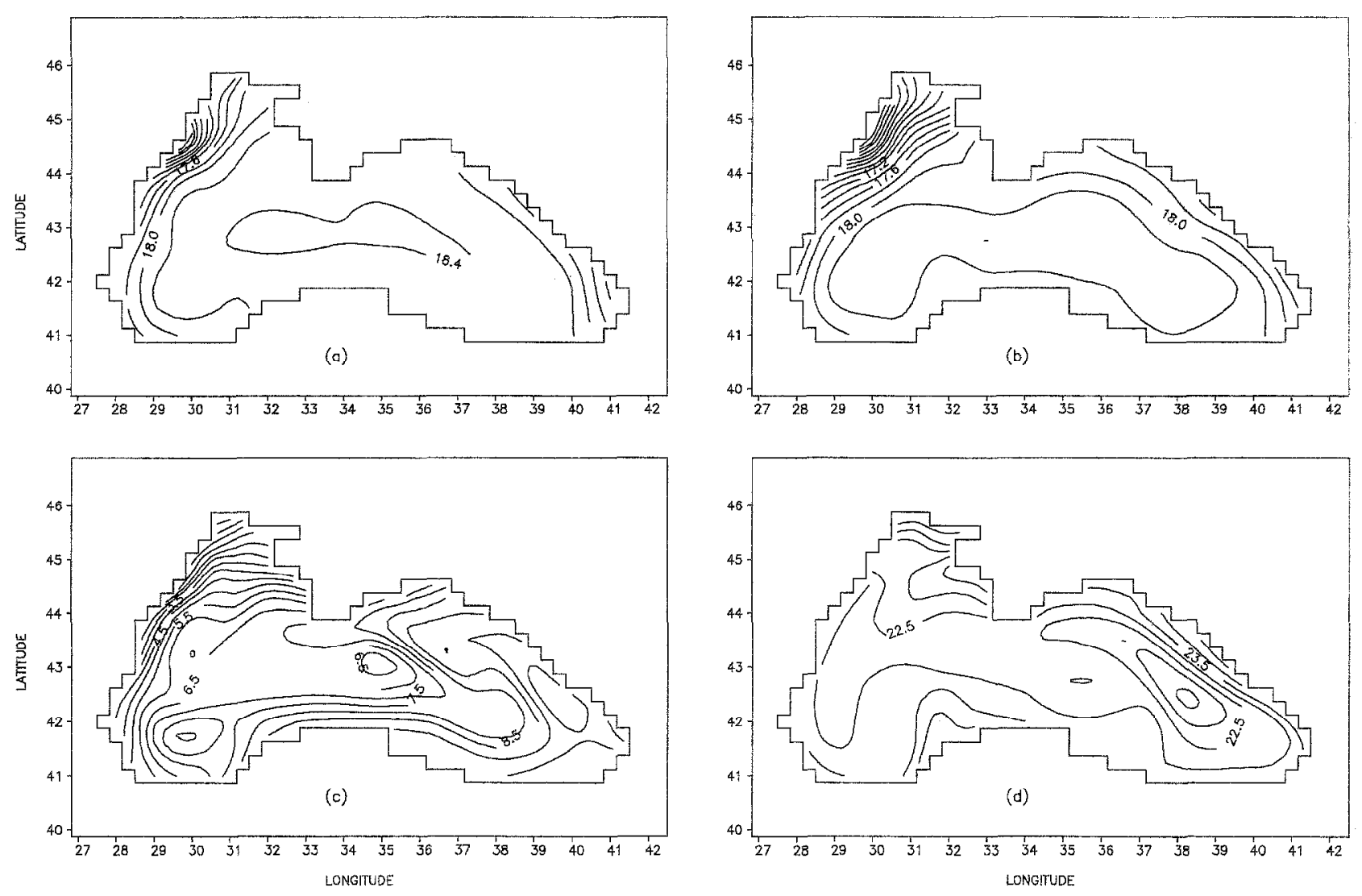

Figure 13. Monthly mean sea-surface salinity ( $\mathrm{a}$ and $\mathrm{b}$ ) and temperature $\left({ }^{\circ} \mathrm{C}, \mathrm{c}\right.$ and $\mathrm{d}$ ) in the MF experiment. a, c) February; b, d) August.

base of the CIL (figure 14). The left column in this figure is for February, the right one for August. The domed patterns correlate with the centres of the circulation gyre. The halocline shows maximum slope in winter in the eastern part of the sea, and in summer in the western part. The simulated data correlate with the climatic data, displayed in the BSHH, as well as with the data obtained during the Hydroblack survey [3]. This proves that the subgrid parameterizations, along with the rest tuning of the model is consistent with the forcing data and with the specific Black Sea conditions.

The temperature cross-sections at $42.7^{\circ} \mathrm{N}$ (figure $14 c, h$ ) illustrate two important and very different thermal states of the sea: (i) the formation of the CIL (figure $14 c$, e.g.); and (ii) the strong stratification in the seasonal thermocline, blocking the vertical exchange (figure $14 d, f, h$ ). Isolines of $8{ }^{\circ} \mathrm{C}$, and lower than this value, are plotted with dash lines to better indicate the position of the CIL.
We discuss below the different simulations for both seasons separately.

The winter ventilation in the MF experiment occurs over most of the basin and reaches about 40-50 $\mathrm{m}$ (the dash isolines in figure $14 \mathrm{c}$ display the depth of the ventilation). A relatively deeper penetration is observed in the westernmost area, which correlates with the well established concept that the cooling is most active in the north-western and western Black Sea. This peculiarity is simulated in all experiments. However, the ventilation is deeper in the SF experiment (figure 14e) than in the remainder of the experiments, due to the different wind forcing. This forcing affects not only the vertical mixing, but also the intensity of the circulation, which provides different conditions for convection (stronger horizontal circulation removes more efficiently the cold water from the area of their origin, thus reducing the depth of convection). The deeper convection in the SF experiment (along with the 


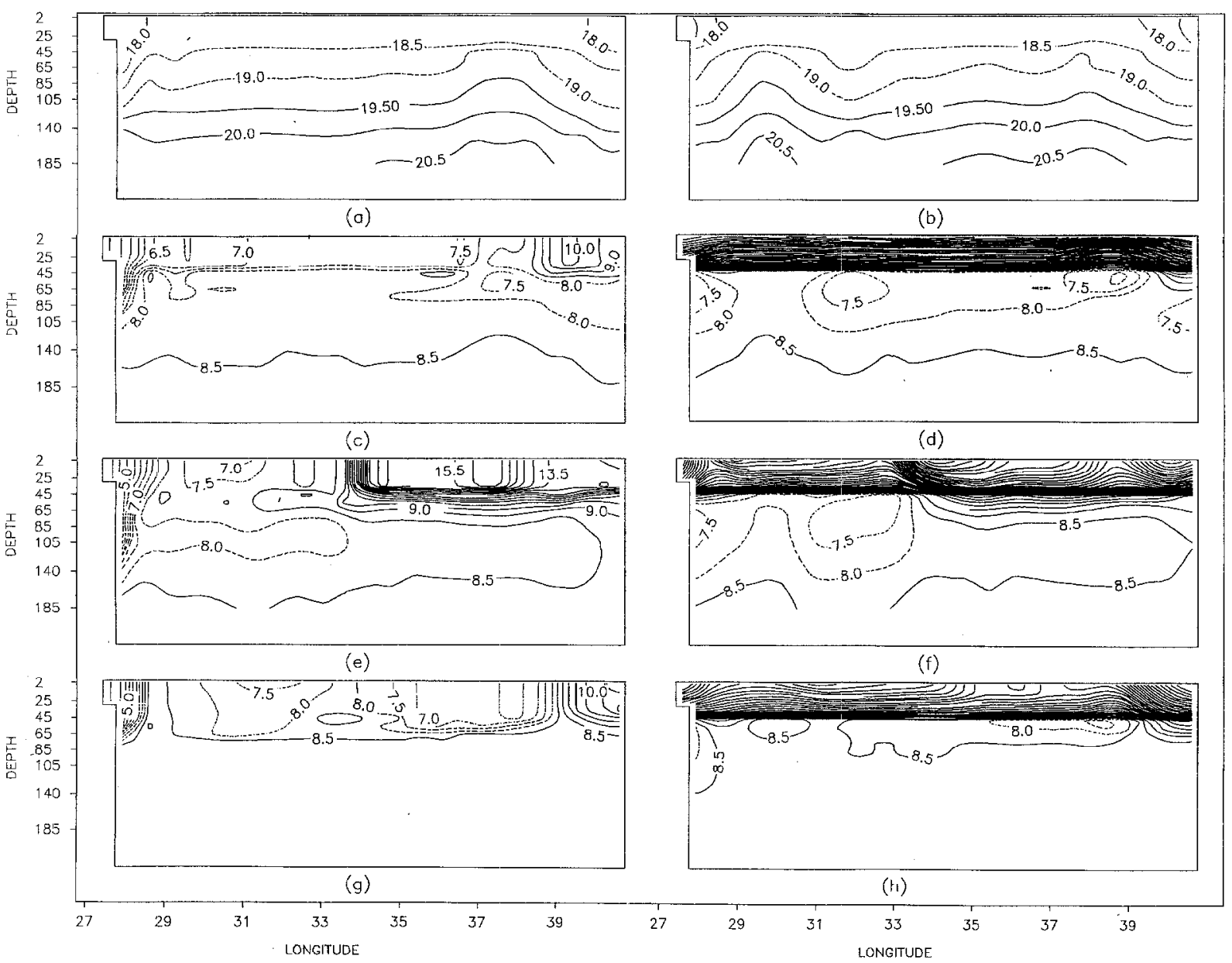

Figure 14. Vertical cross-sections along $42.7^{\circ} \mathrm{N}$ in February (left column) and August (right column). Dash lines correspond to temperature $8{ }^{\circ} \mathrm{C}$ and lower than this value and to salinity 19 and lower than this value. a) salinity in February, MF experiment; b) salinity in August, MF experiment; c) temperature in February, MF experiment; d) temperature in August, MF experiment; e) temperature in February, SF experiment; f) temperature in August, SF experiment; g) temperature in February, CSF experiment; h) temperature in August, CSF experiment.

different stratification, see figure 8) results in the formation of a deeper core of the CIL (figure $14 f$ ) than in the MF experiment (figure 14d).

In the easternmost Black Sea, the ventilation in the MF experiment does not reach the CIL. This also agrees with the concept that cold waters fill the CIL not over the whole surface of the sea, but reach the eastern basin advectively. The area, which is insulated by direct cooling from above, is much larger in the SF experiment (figure 14e). However, the temperatures are unrealistically high in this experiment, reaching about $15^{\circ} \mathrm{C}$ in winter.

The important role of the wind for the formation of the CIL is illustrated by the comparison between the results from the SF and CSF experiments (figure $14 e, g$ ). The abnormally strong heating at the sea surface is avoided in the CSF experiment. However, the convection is too deep over the whole basin in this experiment (figure 14g). This is due to the specific thermohaline forcing in the S-data, affecting the stratification in the intermediate and deep layers (figure 14h).

The seasonal thernocline is very pronounced in all simulations (figure $14 d, f, h$ ). The stratification at the sea surface is strongest in the MF experiment. On the contrary, the stratification in the SF and in the CSF experiments is stronger at about $30-40 \mathrm{~m}$ than in the MF experiment. We recall here that no mixing layer model is embedded in the 
circulation model, so the stratification in the upper layer is mainly due to the stability-dependent vertical mixing coefficients. Apparently, the different forcing data, along with the model feedbacks, tend to establish different vertical stratifications.

\section{CONCLUSIONS}

Many studies on the atmospheric data in the Black Sea exist, but the question of their adequacy as forcing functions for circulation models has never been addressed. This motivated us to attempt a parallel description of the existing climatological data, their sources, and the corresponding model response. We produced model fluxes, which are also used in the intercomparison. Differences between the simulations could roughly give the possible errors in the model estimates if inadequate forcing data are used. Comparisons with the initial data, or with data from other sources, show that the MF experiment adequately simulates the vertical stratification, the seasonal variability and the horizontal patterns. This provides us with arguments for assuming the M-data to be the most adequate model forcing and for describing the MF experiment as a reference one. Some of these arguments are: (i) the net water flux in the M-data is consistent with recent estimates, which are constrained with measurements in the Strait of Bosphorus; (ii) the gradients in the M-data are larger than in the other two climatic data sets, giving at the same time more realistic exchange between the atmosphere and the sea; and (iii) the seasonal variability is also correctly represented in the M-data.

In order not to affect the simulations by the magnitude of the net water balance, we reduce the fluxes in all experiments to $300 \mathrm{~km}^{3} \mathrm{y}^{-1}$. Though the net exchange between the sea and atmosphere is identical in all experiments, there are large differences between the simulations. These are due to the drawbacks of the amplitudes of the seasonal variability, horizontal gradients of the thermohaline forcing, and the wind stress. The last forcing results in excessively deep ventilation in the SF experiment (figure $14 e$ ). This could be due to different wind-induced vertical mixing. However, and more importantly, intensification of the circulation results in pronounced advection and removal of cold water from the area of their origin. This changes the regime of convection and, correspondingly, the water mass formation. Large differences between the simulations forecd by different wind stress and identical thermohaline forcing, as well as inconsis- tencies in the simulations obtained if wind stress of the 5 data is used, provide strong arguments for producing new wind stress in this study. The demonstration that this new mechnical forcing results in more consistent simulations should in turn provide motivations for futher improvements.

The different buoyancy flux at the sea surface governs the magnitude of the seasonal amplitude in the SST and the cold water content in the CIL. The MF experiment gives warmer SST and cooler CIL than the remainder of the experiments. The CIL in the CF experiment is too shallow, and the content of cold water is unrealistically small. The simulations in the CSF experiment are no better, where the CIL practically disappears. In the SF experiment, this layer deepens considerably, and the cold water content decreases strongly, compared to the simulations in the MF experiment. All this shows that simple manipulations in the forcing functions, such as reductions in the net values, can hardly result in substantial improvements in the model simulations.

To our knowledge, the forcing data used here are perhaps very close to the best available at present for the Black Sea. Nevertheless, the model simulations range in large intervals and some of them are very poor. We admit that with more appropriate tuning of the model to every particular forcing data set, small improvements in the simulations could be obtained. This, however, is not the purpose of the present study, which is focused on the intercomparisons between different model responses to different forcing data, given the same physical model.

Actually, the numerical models are far from being able adequately to simulate air-ocean interaction, and the problem of flux correction is a well-known example of the difficulty of finding an appropriate forcing for the ocean model (one part of the coupled atmosphere-ocean physical system). It follows from the results of this study that co-ordinated efforts to update forcing data bases, along with model developments, are called for. Formulating and testing different scenarios (variability, resolutions, parameterizations), both for data and models, also seem to be very important. Perhaps some parameterizations will result in different responses, when applied to different ocean areas, which would make test studies for smaller basins (e.g. the Black Sea, with its well constrained balance) very stimulating. Regarding this particular basin, the elaboration of a common oceanographic database, including atmospheric data, seems of high priority, while improving the existing data sets for atmospheric forcing in some areas, which are rather badly 
represented in the past analyses. Our small contribution to these challenging tasks is to make available to the Black Sea scientific community the data prepared and tested in the present study.

\section{Acknowledgements}

We thank Yu Golubev and E. Ozsoy for providing us with atmospheric data and with high resolution bathymetry. We also thank the anonymous reviewers for their useful comments. This research is funded by the European Union Project EROS-2000 (associated contract ERBCIPDCT940115), and is also supported by the Bulgarian Science Fund.

\section{APPENDIX A.}

\section{Model boundary conditions at the sea surface.}

The model assumes the following boundary conditions at $z=0$ :

$$
\begin{aligned}
& w=0, \rho_{0} A_{\nu} \mathbf{U}_{h_{z}}=\vec{\tau}, \\
& \rho_{0} C_{p} K_{v} T_{z}=q^{T}, \\
& K_{\nu} S_{z}=q^{W} S^{0},
\end{aligned}
$$

or

$$
K_{v} S_{z}=\eta\left(S^{*}-S\right) \Delta z_{1},
$$

where $\mathbf{U}_{\mathbf{h}}$ and $w$ are the horizontal and vertical components of velocity vector, $T, S$-the temperature and salinity. The coefficients of turbulent diffusion in the vertical direction for momentum and heat/salt are $A_{v}$ and $K_{v}$ respectively, $\vec{\tau}$ is the wind stress $q^{T}$ is the net surface heat flux, $q^{W}$ is the water flux at sea surface, $S^{0}$ is constant salinity value, $S^{*}$ is the climatological salinity, $\eta$ is inverse time scale and $\Delta z_{1}$ is the thickness of the first model layer. The net heat flux at the ocean surface can be represented as:

$$
q^{T}=Q_{5}-Q_{U},
$$

where $Q_{S}$ is the downward flux of solar radiation and $Q_{u}$ is the net upward flux of radiation emitted by the sea surface via radiative and evaporative-conductive processes. The parameterization of the terms $Q_{s}$ and $Q_{u}$ will be dis- cussed briefly (for more details we refer to Rosati and Miyakoda, [37]). The net upward flux

$Q_{u}=H_{a}+L E_{a}+Q_{b}$,

includes the net flux of the long wave radiation loss by the sea surface $Q_{b}$, the sensible $H_{a}$ and the latent $L E_{a}$ heat flux $(L$ is the latent heat of vaporization $2.501 \times$ $10^{6} \mathrm{~J} \mathrm{~kg}^{-1}$ ). For the long wave radiation we use the formulae of Berliand and Berliand [4], modified as in the paper of Rosati and Miyakoda [37], and for the sensible and latent heat flux the following bulk formulae:

$H_{a}=\rho_{a} C_{p} C_{h}|\mathbf{W}| \times\left(T_{s}-T_{a}\right)$,

$E_{a}=\rho_{a} C_{e}|\mathbf{W}| \times\left[e_{\text {sat }}\left(T_{s}\right)-r e_{\text {sat }}\left(T_{a}\right)\right] \frac{0.622}{p_{a}}$,

where: $T_{s}$ and $T_{a}$ are the Sea Surface Temperature (SST) and the atmospheric temperature at 1000 mbar respectively, $\varepsilon$ is the emissivity of the sea ( $\varepsilon=0.97,[37]), \sigma$ is the Stefan-Boltzmann constant, $e_{\text {sat }}\left(T_{a}\right)$ is the polynomial approximation [24], $B$ is a correction factor for the effect of cloudiness (0.8), $\rho_{a}$ is the density of the air, $p_{a}$ is the surface air pressure $\left(p_{a}=1013 \mathrm{mbar}\right),|\mathbf{W}|$ is the surface winds magnitude, $C_{p}$ is the specific heat capacity, $C_{p}=1.005 \times 10^{3} \mathrm{~J} \mathrm{~kg}^{-1} \mathrm{~K}^{-1}, C_{h}, C_{e}$ are the turbulent exchange coefficients.

The momentum flux is given by the wind stress components:

$\left(\tau^{\lambda}, \tau^{\varphi}\right)=\rho_{a} C_{d}|\mathbf{W}|\left(W_{x}, W_{y}\right)$,

where $W_{x} W_{y}$ are the wind components, $C_{d}$ is the drag coefficient.

Momentum and heat fluxes are calculated interactively. The model calendar is set to correspond to the real time of the atmospheric data set (the atmospheric data are interpolated at every time step from available data). The model time is used to calculate the solar radiation at every grid point. The fractional cloud cover is inferred at each model step from monthly mean data [41]. The value of $T_{s}$ in the expressions for the wind stress and for the net upward flux is equal to the current model SST.

\section{APPENDIX B.}

The model fresh water balance and the parameterisation of the Mediterranean plume

The boundary condition (A 3a) prescribes explicitly the sea surface salt flux from the climatic data. Alternatively, 
when we use the boundary condition ( $A 3 b$ ), this flux is computed in the model and the basin integrated restoring term is:

$Q_{s}(t)=\iint \eta\left(S^{*}-S\right) d x d y \Delta z_{1}$.

Having in mind equation A 3a, we can estimate the cor responding basin averaged fresh water flux:

$Q_{w}(t)=\frac{Q_{s}(t)}{S^{0}}$.

We use the fresh water flux (no matter how it is calculated, from data, or from model restoring term) to force a simple model, parameterizing the Bosphorus inflow. The time variations in the net water balance $Q_{W}$ affect the transport in the strait. Hydraulic control theory enables to parameterize the exchange in the strait with different level of complexity $[25,28,31,44,47]$. Below, we proceed in terms of water fluxes and use a simple linear formula, relating the undercurrent $Q_{2}^{*}$ and the barotropic $Q_{0}$ transports (figure 9 of [28]):

$Q_{2}^{*}=(a-1) Q_{0}+b$,

where $a=0.5$ and $b=13000 \mathrm{~m}^{3} \mathrm{~s}^{-1}$. The time variability of $Q_{W}$ (figure $7 b$ ) indicates largest fresh water flux in spring-summer (negative values).

The barotropic transport in the strait depends on the fresh water gain at the sea surface $Q_{w}$, but they are not identical at every time step. We smooth the oscillations in $Q_{W}$, with a time window $T$ :

$Q_{0}(t)=\frac{1}{T} \int_{t-T}^{t} Q_{W}(t) d t$,

This equation suggests a time lag between the barotropic transport and the fresh water gain at sea surface, and is consistent with the observations $[40,47]$. If, instead of equation B 4 we assume $Q_{0}=Q_{W}$ we could have negative values for the barotropic transport (figure 7). However, this flow does not seem to reverse, at least due to the seasonal variability in the fresh water flux. There are indeed some observations (Emin Ozsoy, personal communications) that reversals are possible, but this is rather a response to the local winds. 'The constraint to have unidirectional transport requires larger time window, $T$, in equation B 4. Our sensitivity experiments with relaxation boundary condition (A $3 b$ ) showed that $T=120$ day gives realistic phase differences and unidirectional barotropic transport (figure $7 b$ ).
With the time variable sea surface flux and the inflow computed from equation B3 we could have a salt deficit in the model, which accumulates in time:

$\Delta^{s}(t)=\int_{t_{0}}^{t}\left[\left(Q_{W} S^{0}+Q_{2}\left(S_{M}-S\left(z_{0}\right)\right)\right)\right] d t$,

where $S_{M}$ is the salinity of the Mediterranean Sea, and $S\left(z_{0}\right)$ is the salinity of the Black Sea water at the depth where the inflow is specified.

If we take the values 36 and 18 for the Mediterranean/ Black Sea salinity, correspondingly, the above cquation simplifies as:

$\Delta^{s}=18 \Delta^{w}$, where $\Delta^{w}(t)=\int_{t_{0}}^{t}\left(Q_{w}+Q_{2}\right) d t$.

To minimise $\Delta^{W}$ we modify the inflow $Q_{2}$ by adding a correction term to equation B 3 a, which is proportional to the total for the period before the current time water deficit:

$Q_{2}=Q_{2}^{*}+\gamma \Delta^{W}$

The accumulated imbalance is changed, correspondingly: $\Delta^{w}=\Delta^{w}-\gamma \Delta^{W}$

The coefficient $\gamma$ shows how fast the Black Sea adjusts to the fresh water variability with long time scales. The idea behind this parameterization correlates with the observational evidence that the height of the Black Sea over the Mediterranean Sea and its volume mean salinity do not show pronounced trends for the last hundred years. With the above feedback we force the model to conserve the water content in a long run. The strength of this feedback has been chosen after carrying out number of sensitivity runs as $\gamma=1 / 365$ day $^{-1}$. In these experiments the net fresh water flux at the sea surface, the corresponding transports in the strait and their time variability are fitted to the observations [49].

We specify in the model the inflow $Q_{2}$ at depth, corresponding to the sill depth of the strait, and neglect the contribution of momentum of the Bosphorus inflow on the adjacent water column as a small one. Thus, we affect the model equations for $T$ and $S$, but not directly the momentum equations. According to the theory of sinking plumes [48]

$\frac{1}{V} \frac{d V}{d z}=2 \frac{\alpha}{b}$

where $d V$ is the increase of the volume of the plume at depth $z, b$ is its radius, and $\alpha$ is constant. 
The parameterization (figure 15), suggests a virtual convective element (thermal) with a square base $\Delta x, \Delta y$. At model level $k$, it has a thickness $h_{k}$, temperature $T_{k}$, and salinity $S_{k}$, This element entrains water from the ambience and increases its volume. This results in a decrease of the volume of the ambient water, and corresponds to an upward displacement of the water column. Thus, the thermal penetrates deeper, increasing its volume and decreasing its density. These processes make the plume behave as a "mixing agent" [38] rather than only transporting water downward. The interested reader can find results of 1-D model simulations with similar plume parameterization, and for the neighbouring sea of Marmara, in the paper of Besiktepe et al. [5].

Taking into account the geometry of the model convective element, we write in equation $\mathrm{B} 8 d V=b^{2} d h$, where $b^{2}=\Delta x, \Delta y$, and $d h$ is the increase of the thickness of the sinking plume. Since $b=$ const ( $h$ is variable), equation $\mathrm{B}$ 8 yields

$d h=\frac{h}{\mathbf{H}} d z$,

where $\mathbf{H}$ is the penetration depth, at which the initial volume $V_{0}=b^{2} \quad h_{0}$ (equal to the inflow water per time step) increases $e$ fold due to entrainment. Since the thick- ness of the plume obeys an exponential law, we can rewrite equation B 9 in terms of entrainment/detrainment (the water entrained through the side of the model column amounts to $\varepsilon b^{2} \Delta h_{k}$, and the detrained one to $\delta b^{2} \Delta h_{k}$, see figure 15):

$\frac{\Delta h_{k}}{\Delta z_{k}}=\frac{4(\varepsilon-\delta)}{b} h_{k}$

so that

$\frac{1}{\mathbf{H}}=\frac{4(\varepsilon-\delta)}{b}$.

The increase of the plume thickness is compensated for by a decrease in the ambient water at level $k$. This is compensated by a vertical displacement of $(\varepsilon-\delta) b^{2} \Delta h_{k}$ water from level $k+1$ into the level $k$ (figure 15c). From the conservation of heat, salt, and mass in the plume and in the ambience we can write equations for the salinity of the plume and of the water column [45].

We tune the model entrainment to the observations of Buesseler et al. [11], who estimate the ratio of the entrained Black Sea water versus the inflowing Mediterranean Sea water as 3:1 for the upper $150 \mathrm{~m}$ layer. Following Gregory and Rowntree [18], who postulated $\delta=1 / 3 \varepsilon$, we have $\delta=1$.

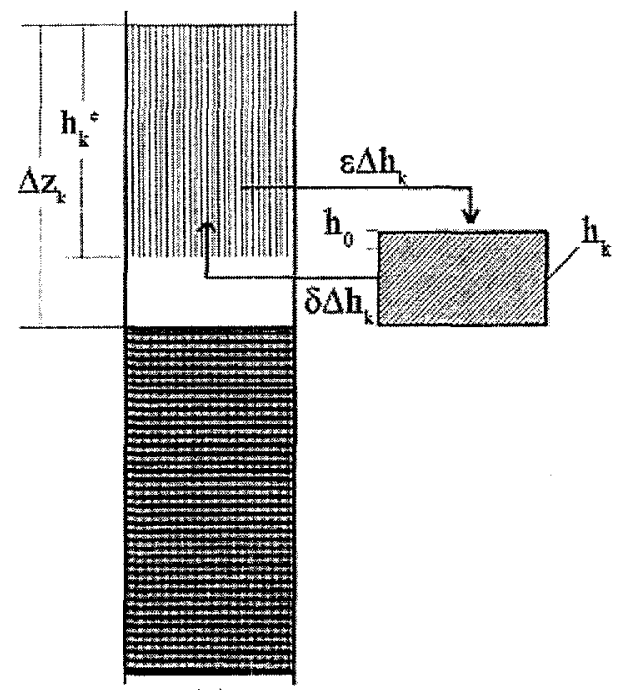

(a)

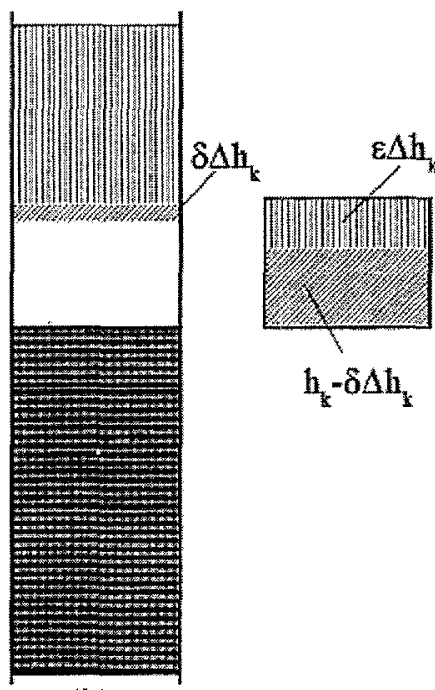

(b)

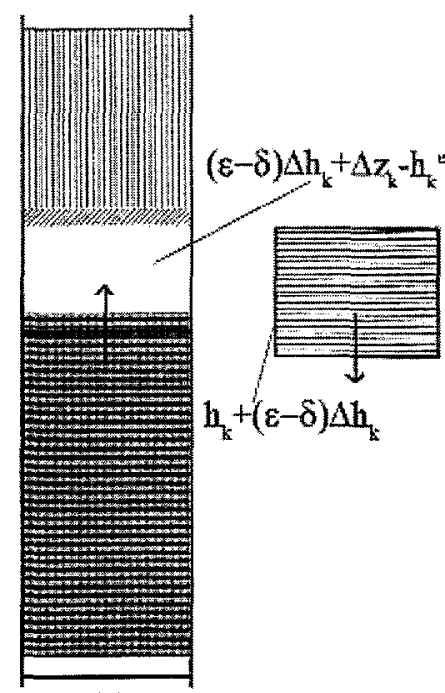

(c)

Figure 15. Parameterization of the sinking plume. The initial volume $V_{0}=b^{2} h_{0}$, which equals the inflow per time step, exchanges water with the ambience (the model grid column adjacent to the strait). The entrained water $\left(\varepsilon \Delta h_{k}\right)$ exceeds the detrained one $\left(\delta \Delta h_{k}\right.$,), thus the thickness of the convective element increases (b) and the thickness of the ambient (the water column) decreases. The height of the "empty part" of the column is equal to the increase of the plume thickness $h_{k}-h_{0}$. The initial height of the ambience column at level $k$ (a) is thus $h_{k}{ }^{e}=\Delta z_{k}-\left(h_{k}-h_{0}\right)$. The increase of the thickness of the convective element and the decrease of the thickness of the water column induce a displacement of the water column from below (c). 
[1] Altman E.N., Gertman I.F., Golubeva Z.A., Climatic salinity and temperature tields of the Black Sea, SO, GOIN, Sevastopol (1987), 110 p. (in Russian).

[2] Altman E.N., Kumish N.I., Interannual and seasonal variability of the Black Sea fresh water balance, Trudy Gos. Oceanogr. Inst. 145 (1986) 3-15, (in Russian).

[3] Aubrey D.G, Oguz T., Demirov E., Ivanov V., McSherry T., Diaconu V., Nikolaenko E., Hydroblack'91 CTD intercalibration workshop, UNESCO, Intergovernmental Oceanographic Commission, Workshop report No 91 (1991), $56 p+6$ annexes.

[4] Berliand M.E., Berliand T.G., Measurement of the effective radiation of the Earth with varying cloud amounts, Izv. Akad. Nauk, SSSR, Ser. Geoliz. 1 (1952) 64-78. (in Russian).

[5] Besiktepe S., Ozsoy E., Unluata U., Filling of the Marmara Sca by the Dardalelles lowcr layer inflow. Decp Sca Res. 1, 40 (1993) 1815-1838.

[6] Blatov A.S., Bulgakov N.P., Ivanov V.A., Kosarev A.N., Tujilkin V.S., Variability of hydrophysical fields in the Black Sea. Gidrometeoizdat Leningrad (1984) 240 p. (in Russian).

[7] Bogdanova A.K., Seasonal and interannual variations in the Bosphorus exchange, in Biologyia Moria, 27 (1972) 41-54, Naukova Dumka, Kiev (in Russian).

[8] Bryan F., High-latitude salinity effects and interhemispheric thermohaline circulations. Nature 323 (1986) 301-304.

[9] Bryan K., A numerical method for the study of the circulation of the World Ocean, J Comp. Phys. 3 (1969) 347-378.

[10] Budyko M.I., The heat balance of the Earth's surface. English translation by N. A. Stepanova, U.S. Weather Bur. Washington, D. C. (1958) 259 p.

[11] Buesseler K.O., Livingston II.D., Casso S.A., Mixing between oxic and anoxic waters of the Black Sea as traced by Chernobyl cesium isotopes, Deep-Sea Res. 38 (1991) S725-S745.

[12] Bulgakov S.N., G.K. Korotaev, Whitehead J.A., The role of Buoyancy Fluxes in the Formation of a Large-Scale Circulation and Stratification of the Sea Water. Part 1: The Theory. Phys. Atmosph. and Ocean 32 4, (1996) 548-556 (in Russian).

[13] Cai W.R., Greatbatch J., Zhang S., Interdecadal variability in an ocean model driven by a small zonal redistribution of the surface buoyancy flux, J. Phys. Oceanogr. 25 (1995) 1988 2010.

[14] Efimov F.V., Timofeev A., Studies on the heat balance of the Black Sea and Azov Sea. Marine Hydroph. Inst. Press, Obninsk (1990) 121 p. (in Russian)

[15] Filippov D.M., Circulation and water composition of the Black Sea, Nauka, Moscow (1968) 136 p.

[16] Gargett A.E., Vertical eddy diffusivity in the ocean interior, J. Mar. Res. 42 (1984) 359-393.

[17] Golubeva A., Variability of the Black Sea heat balance. Trudy GOIN, 180 (1984) 21-32 (in Russian).
[18] Gregory D., Rowntree P., A mass flux convection scheme with representation of cloud ensemble characteristics and stability dependent closure, Mon. Weather Rev. 118 (1990) 1483-1506.

[19] Gulev S.K., Influence of space-time averaging on the oceanatmosphere exchange estimates in the North Atlantic midlatitudes, J. Phys. Oceanogr. 24 (1994) 1236-1255.

[20] Hellerman S., Rosenstein M., Normal monthly wind stress over the World Ocean with error estimates, I. Phys. Oceanogr. 17 (1983) 158-163.

[21] Huang R.X., Real freshwater flux as a natural boundary condition for the salinity balance and thermohaline circulation forced by evaporation and precipitation, J. Phys. Oceanogr. 23 (1993) 2428-2446.

[22] Kiuchukova M.K., Editor, Climatic handbook of Bulgaria, vol. 4, Wind. Nauka i Izkustvo, Sofia, 1982 (in Bulgarian).

[23] Lewis B.L., Landing W.N., Manganese and iron in the Black Sea, Deep-Sed Res. 38 (1991) S773-\$805.

[24] Lowe P.R., An approximating polynomial for the computation of the saturation vapour pressure, J. Appl. Met. 16 (1977) 100103.

[25] Maderich V.S., Efroimson V.O., A simple model of a sca with the strait, Okeanologia 26 (1986) 402-408, (in Russian).

[26] Makerov Y.V., Heat balance of the Black Sea. Trudy GOIN, Moscow, 61 (1961) 169-183 (in Russian).

[27] Oberhuber J.M., The OPYC Ocean general circulation model, Deutsches KlimaRechnenZentrum, Technical Report No 7 (1993) $130 \mathrm{p}$.

[28] Oguz T., Ozsoy E., Latif M.A., Sur H.I., Unluata U., Modeling of hydrographically controlled exchange flow in the Bosphorus Strait., J. Phys. Oceanogr. 20 (1990) 945-965.

[29] Oguz T., Malanotte-Rizzoli P., Seasonal variability of wind and thermohaline driven circulation in the Black Sea, J. Geophys. Res. 101 (1996) 16551-16569.

[30] Oguz T., Malanotte-Rizzoli P., Aubrey D., Wind and thermohaline circulation of the Black Sea driven by yearly mean climatological forcing, J. Geophys. Res. 100 C4, (1995) 68466865.

[31] Ozsoy E., Latif M.A., Sur H.I., Goryachkin Y., A review of the exchange Flow regimes and mixing in the Bosphorus Strait, in: F. Briand, (editor), Mediterranean Tributary Seas, Bulletin de l'Institut Oceeanographique, Monaco, Special Number 17 , CIESM Science Series No. 2, Monaco (1996).

[32] Ozsoy E., Unluata U., Top Z., The evolution of Mediterranean water in the Black Sea: interior mixing and material transport by double diffusive intrusions. Progr. Oceanogr. 31 (1993) 275-320.

[33] Pakanowski, R.C., Dixon K., Rosati A., The GFDL Modular Ocean Model Users Guide, version 1.0. GFDL Ocean Group Tech. Rep. No 2, (1991) 176 p. 
[34] Power S.B., Kleeman R., Multiple equilibria in a global ocean general circulation model. J. Phys. Oceanogr. 23 (1993) 1670 1681 .

[35] Rachev N.H., Roussenov V.M., Stanev E.V., The Black Sea climatological wind stress, Bulgarian J. Meteol. Hydrol. 2 (1991) 72-79.

[36] Rachev N.H., Stancv E.V., Eddy processes in semi-cnclosed seas. A case study for the Black Sea, J. Phys. Oceanogr. 27 (1997) 1581-1601.

[37] Rosati A., Miyakoda K., A general circulation model for the upper ocean simulation, J. Phys. Oceanogr. 18 (1988) 16011626.

[38] Send U., Marshall J., Integral effects of deep convection, J. Phys. Oceanogr. 25 (1995) 855-872.

[39] Shahanova T.V., Shutova E.I., Results from a study on the external heat budget of the Black Sea on the R/V "Michail Lomonosov". Comp. Mar. Hydrophys. Inst., Sevastopol 38 (1967) 92-101.

[40] Simonov A.I., Altman E.N., Editors Hydrometeorology and hydrochemistry of the USSR seas. Vol. IV. The Black Sea. Gidrometeoizdat (1991) 430 p.

[41] Sorkina A I., Editor Reference book on the Black Sea climate (in Russian). Gidrometeoizdat, Moscow (1974) 406 p.
[42] Stanev E.V., Numerical study on the Black Sea circulation. Mitteilungen des Instituts für Meereskunde der Universitaet Hamburg, 28 (1988) 232 p.

[43] Stanev E.V., On the mechanisms of the Black Sea circulation, Earth-Science Rev. 28 (1990) 285-319.

[44] Stanev E.V., Roussenov V.M., Rachev N.H., Staneva J.V., Sea response to atmospheric variability. Model study for the Black Sea. J. Mar. Sys. 6 (1995) 241-267.

[45] Stanev E.V., Staneva J.V., Roussenov V.M., On the Black Sea water mass formation. Model sensitivity study to atmospheric forcing and parameterization of some physical processes, J. Mar. Sys. 13 (1997) 245-272.

[46] Staneva J.V., Stanev E.V., Rachev N.H., Heat balance estimates using atmospheric analysis data. A case study for the Black Sea, J. Geophys. Res. 100 C9 (1995) 18581-18596.

[47] Tolmazin D., Changing coastal oceanography of the Black Sea. Part II: Mediterranean effluent, Progr. Oceanogr. 15 (1985) 277-316.

[48] Turner J.S., Buoyancy effects in fluids. Cambridge University Press (Translation in Russian, Izd. Mir, Moscow, 1977) (1973) $431 \mathrm{p}$.

[49] Unluata U., Oguz T., Latif M.A., Ozsoy E., On the physical oceanography of the Turkish Straits, in: The Physical Oceanography of Sea Straits, NATO ASI Ser., Ser. C, (ed.) by G. Pratt, p. 25-60, Kluwer Academic, Norwell, Mass (1990). 